\title{
A Review on Prevention of Sticking during Fluidized Bed Reduction of Fine Iron Ore
}

\author{
Lei GUO, ${ }^{1)}$ Qipeng $\mathrm{BAO}^{1)}{ }^{1)}$ Jintao $\mathrm{GAO},{ }^{1) *}$ Qingshan $\mathrm{ZHU}^{2)}$ and Zhancheng GUO ${ }^{1)}$ \\ 1) State Key Laboratory of Advanced Metallurgy, University of Science and Technology Beijing, Xueyuan Road No. 30, Haidian \\ District, Beijing, 100083 China. \\ 2) State Key Laboratory of Multiphase Complex Systems, Institute of Process Engineering, Chinese Academy of Sciences, \\ Beijing, 100190 China.
}

(Received on June 26, 2019; accepted on July 29, 2019; J-STAGE Advance published date:

November 7, 2019)

\begin{abstract}
The fluidized bed ironmaking technology has attracted the attention of many researchers for decades as a direct reduction ironmaking method with many advantages. This process has been applied as a pretreatment method in many non-blast furnace ironmaking processes. However, the sticking problem hindered its development greatly. Defining the essential cause of sticking, and fundamentally solving this problem are the key steps encountered by this process. The research works related to the prevention of sticking problem during fluidized bed reduction of fine iron ore are comprehensively summarized in this article. The causes of sticking, the influencing factors of sticking and the solution of sticking are firstly discussed, followed by the analysis on the possible development direction of future fluidized bed ironmaking technology.
\end{abstract}

KEY WORDS: fluidized bed; fine iron ore; sticking; agglomeration; iron whisker.

\section{Introduction}

The most important feature of fluidized bed ironmaking process is that the fine iron ore can be directly used without any sintering or pelleting processes, which can save 25-30 US dollars/ton of iron in raw material cost and reduce the cost of sponge iron by $25 \%{ }^{1)}$ It is reported that the FIOR method using fluidized beds cost only half of the material cost of the MIDREX method using a shaft furnace. ${ }^{2}$ The iron ore fines have a large specific surface area. During the fluidization reduction process, the particles continuously fluidize and collide under the agitation of the gas stream, and the gas-solid phases get good contact, which accelerates the heat and mass transfer and chemical reaction speed between the particles and the fluid. The flow of fluidized particles can move like liquids, which provides conditions for continuous operation and automatic control of the fluidized bed.

In addition, this direct reduction ironmaking process also has outstanding advantages in terms of economy and environmental protection. Economical: The fluidized bed ironmaking process has a clear advantage in fixed asset investment and production cost compared to the blast furnace process. According to the introduction of FINEX process from official Siemens, a FINEX plant with an annual output of 1.5 million tons is more cost effective than a blast furnace ironworks with an annual output of 3 million tons. If the oxygen production process and power plant process

\footnotetext{
* Corresponding author: E-mail: jintaogao@ustb.edu.cn DOI: https://doi.org/10.2355/isijinternational.ISIJINT-2019-392
}

are taken into account, the fixed asset investment and operating costs of the FINEX process will be about 15-20\% lower than the blast furnace ironworks of the same size. ${ }^{3)}$ Environmentally friendly: $\mathrm{SO}_{\mathrm{x}}, \mathrm{NO}_{\mathrm{x}}$ and dust emissions from the fluidized bed ironmaking process are much lower than the blast furnace process due to the elimination of two high-pollution and high-emission processes of coking and sintering. ${ }^{4)}$ The sulfur component in the non-coking coal used in this process reacts with limestone forming into $\mathrm{CaS}$, which is fixed in the smelting slag. So that the discharge of $\mathrm{SO}_{\mathrm{x}}$ gas in the blast furnace process is avoided. Different from the oxidizing atmosphere in sintering and coking processes, the reaction of the fluidized bed ironmaking process mainly occurs under a reducing atmosphere, thereby avoiding the generation of $\mathrm{NO}_{\mathrm{x}}$ gas and reducing its emissions. The highly integrated and closed process avoids dust emissions, and its relatively low operating temperature avoids the production and emission of high carcinogens such as dioxins. The gas-based fluidized bed reduction process also provides technical support for the development of clean ironmaking processes with the non-carbon-based reducing agent.

Compared with the blast furnace, due to the lower operating temperature, the gangue phase is not easily reduced into the metallic iron phase, so the fluidized bed ironmaking process is more conducive to the treatment of complex paragenic iron ore. ${ }^{5)}$ For example, in the treatment of vanadium-titanium magnetite, the vanadium-titanium element can be prevented from entering into the metallic iron phase during the direct reduction process, and higher-quality 
titanium slag can be obtained by the subsequent melting separation process without using a large amount of flux. ${ }^{6,7)}$ For the treatment of high phosphorous iron ore, the fluoroapatite phase will not be reduced during the direct reduction process, thus avoiding the dissolution of phosphorus into the metal iron phase, which is beneficial to the later phosphorus removal operation. ${ }^{8)}$

It is estimated that China's annual scrap production will reach 210 million tons by 2020, and will reach 310 million tons in 2030.9) By 2050, the global steel production is expected to reach 2.8 billion tons per year, and with the increase in long-process scrap ratios and the development of all-steel electric furnaces, $50-70 \%$ of steel production will depend on scrap. ${ }^{10)}$ The recycling process of scrap steel requires the use of direct reduced iron as a diluent. As the scrap processing capacity increases, a large amount of direct reduced iron is consumed. As of 2017, global direct reduced iron production has reached a record high of 87.1 million tons, and it is still increasing year by year. ${ }^{1,11)}$

The fluidized bed can be combined with some smelting reduction furnaces such as a smelting gasifier, an iron bath furnace or an electric furnace. Then the fluidized bed is used as a pre-reduction setup using its good gas-solid reaction conditions. The main processes involved in fluidized bed are FIOR method, FINMET method, H-IRON method, NU-IRON method, HIB method, DIOS method, FINEX method, FROLTS method, CIRCOFER method, CIRCORED method, ELRED method and so on. ${ }^{12-21)}$

In the practical production, the amount of gas required to maintain the fluidization of the material is much larger than the amount of gas consumed by the reduction reaction, resulting in a low utilization rate of the reducing gas and high energy consumption of the gas cycle. If the particle size range of ore fines is wide, it is easy to cause the small-size ore fines to be carried out under the drag force of the high-speed airflow, causing elutriation. The elutriation of the ore fines not only causes the blockage of the pipeline, but also affects the stable operation of the fluidized bed, and also causes the loss of raw materials. Therefore, an efficient dust collecting device has to be set up in the process, which increases the complexity of the construction and operation of the equipment. In addition, in the late stage of fluidization reduction, the iron ore particles are prone to stick together, and then develop into the de-fluidization of the entire bed. ${ }^{22}$ ) Throughout all the problems in fluidized bed ironmaking, the most difficult is the problem of sticking. This problem will lead to the sudden stop of fluidization, causing interruption of production. Some researchers have done a lot of work in exploring methods to prevent the sticking problem, but the research direction is too scattered, lack of horizontal comparison and summative evaluation. So the authors believe that this review article is needed to be written for the comparison and evaluation of various studies, proposing an optimized solution for the sticking problem and looking forward to the possible future development of fluidized bed ironmaking.

\section{The Cause for Sticking Problem}

Scholars have been exploring the cause for the sticking problem during fluidized bed reduction of fine iron ore for decades. However, there is still no clear explanation for its mechanism, which is universally recognized by the academic circles. The main ideas on the mechanism of sticking are as follows.

\subsection{The Bonding Effect of Iron Whiskers}

Whisker is very common, it can be found in electronic components ${ }^{23)}$ and it can be produced during vapor deposition, ${ }^{24)}$ reduction of iron oxide ${ }^{25}$ and cooling of wustite. $^{26)}$ Some whiskers such as carbide, ${ }^{27)}$ nitride, ${ }^{28)}$ oxide, ${ }^{29)}$ et al. are used for the preparation of composite materials due to their high elastic modulus and other characteristics, thereby improving the toughness of the material. $^{30,31)}$ However, sometimes whiskers can cause problems, such as metal whiskers in electronic components can cause short circuit, ${ }^{23)}$ iron whiskers produced during the gas-based reduction of iron ore fines will cause the
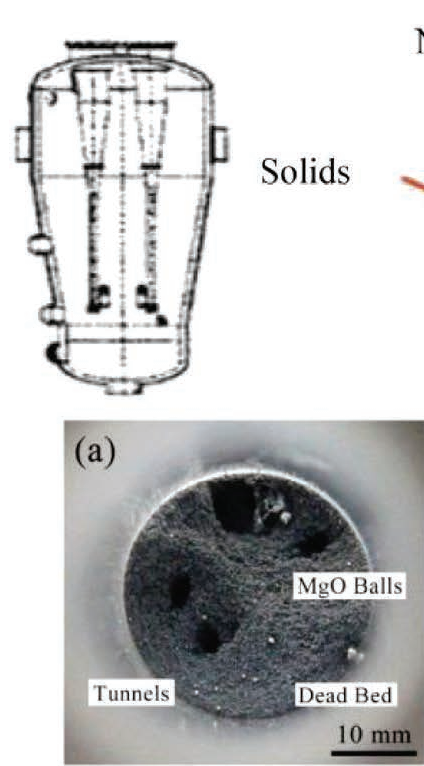

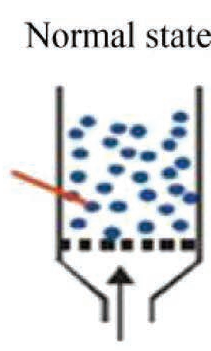

Gas

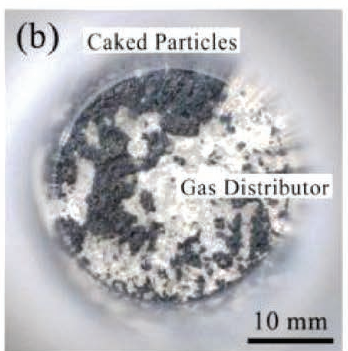

Start sticking De-fluidization

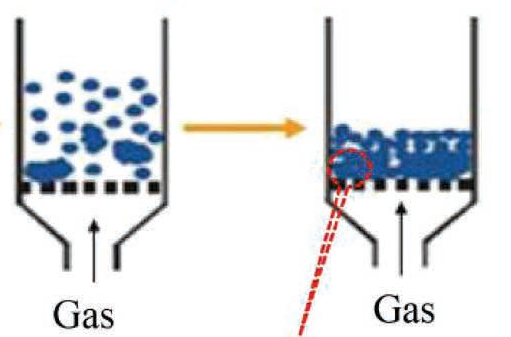

(c)

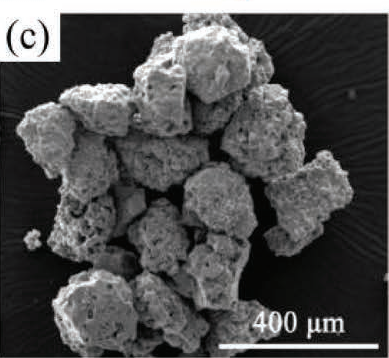

Fig. 1. The schematic diagram of the sticking problem during fluidized bed reduction of fine iron ore. (Online version in color.) 
agglomeration of iron ore particles. An iron whisker ${ }^{32)}$ with a diameter of about $1.6 \mu \mathrm{m}$ has a tensile strength of 13400 $\mathrm{MPa}$, which is 4-10 times higher than that of ultra-high strength steel. Therefore, when the surface of the iron ore particles is enriched with high-strength iron whiskers, and they are bonded to each other, it will result in an increase in the mutual movement resistance among the particles during the fluidization process, so that the fluidization cannot be maintained and the de-fluidization occurs, ${ }^{33-38)}$ as shown in Fig. 2.

Different reduction conditions have different effects on the surface morphology evolution during the reduction of iron ore fines. ${ }^{40)}$ The study by C. Wagner ${ }^{41)}$ and M. Schiller ${ }^{42)}$ suggests that the precipitation morphology of metallic iron during gas-based reduction is mainly caused by the joint influence of temperature and reduction potential $\left(\mathrm{CO} /\left(\mathrm{CO}+\mathrm{CO}_{2}\right)\right.$ or $\left.\mathrm{H}_{2} /\left(\mathrm{H}_{2}+\mathrm{H}_{2} \mathrm{O}\right)\right)$. A schematic diagram of the relationship between the different morphology of metallic iron and the two influential factors is displayed in Fig. 3.

S. P. Matthew et al. ${ }^{4-48)}$ conducted in-depth research on the evolution of surface morphology under different reducing conditions of iron oxide in the 1980s and 1990s, and found that due to the difference in conditions like temperature and reduction potential it will show three kinds of morphologies of dense, porous and fibrous (the iron whiskers belong to this type) on the surface of the ore fines. The dense type is formed at a low temperature and high reduction potential, the porous type is formed at a high temperature and high reduction potential, and the fiber type is formed at a lower reduction potential in the middle-temperature range. For the reasons on the formation of these three kinds of morphologies, some scholars have made the following explanations: $:^{33,49-52)}$ the reduction process of the entire particle contains two main steps, the migration of oxygen atoms (including the migration of oxygen atoms to the surface and the surface reduction reaction) and the migration of newly formed iron atoms based on the mechanism of vacancy diffusion. (1) When the inward migration velocity of newly formed metal iron atoms on the surface of the particle is much smaller than the generating rate of metal iron atoms on the surface of the particle, it is the diffusion control situation. Then the metal iron atoms are limited to the surface of the particles, and the critical nucleation free energy upper limit can be reached in a short time.
When a certain degree of metal iron atom accumulation is reached, the surface begins to form dispersed iron nuclei, at which time the free energy of the iron atoms returns to the critical value. As the oxygen atoms migrate and the reaction proceeds, new metal iron atoms are continuously filled into the iron nuclei until the dispersed iron nuclei are connected into a lamellar shape to form a dense surface, as shown in Fig. 4(a). (2) When the generating rate of the metallic iron atoms on the surface is equivalent to the inward diffusion rate of metal iron atoms, this is the mix control situation. At this time, the metal iron atoms diffuse in a limited area and the supersaturated region exists only in a part of the entire particle. The surface iron atom free energy exceeds its critical nucleation free energy at multiple locations, and some iron nuclei appear over time. There are two sources of iron atoms that support the growth of these iron nuclei, one is the diffusion of iron atoms from the supersaturated region and the other is the iron atoms produced by the continuous chemical reaction on the surface. With the replenishment of iron atoms, the iron nuclei grow and form into a conical shape, and the surface of the ore fines form a porous surface, as shown by Fig. 4(b). (3) When the generating rate of iron atoms on the surface of the particles is much slower than the rate at which they migrate into the interior of the particles, it is the reaction control situation. At this point,

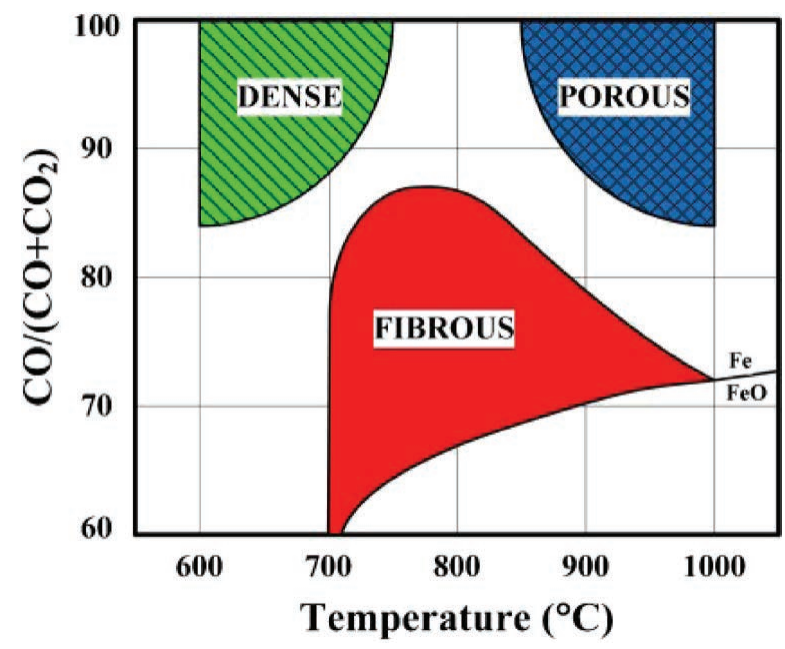

Fig. 3. The morphology of iron ore particles under different temperatures and atmosphere. ${ }^{43)}$ (Online version in color.)
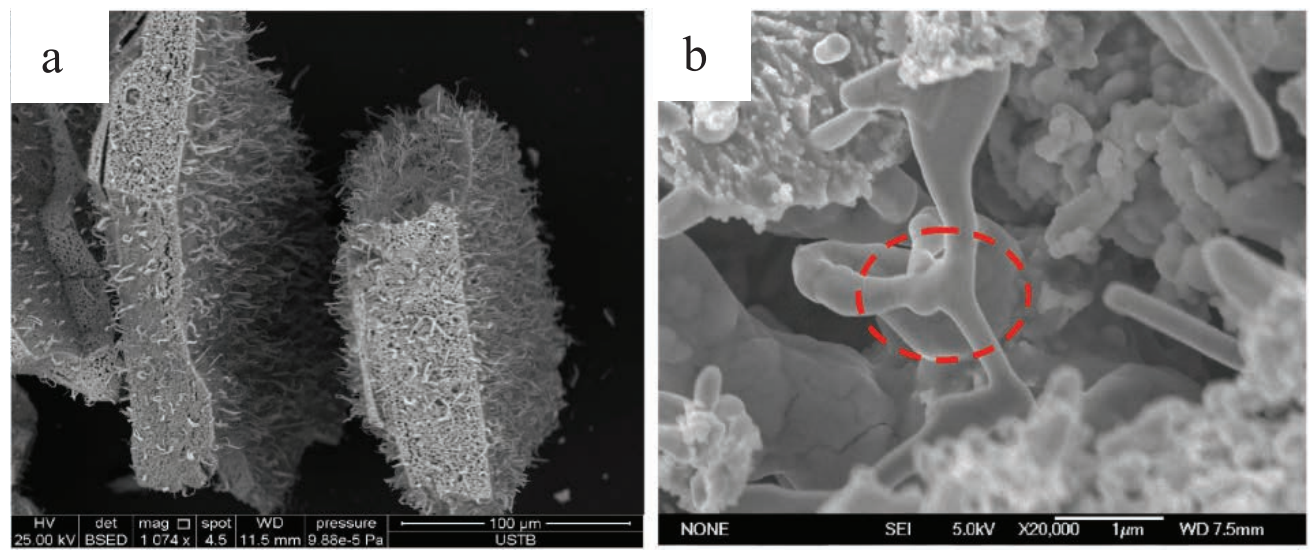

Fig. 2. The morphology of iron ore particles with iron whiskers (a) and the bonding phenomenon between iron whiskers (b). ${ }^{39)}$ (Online version in color.) 


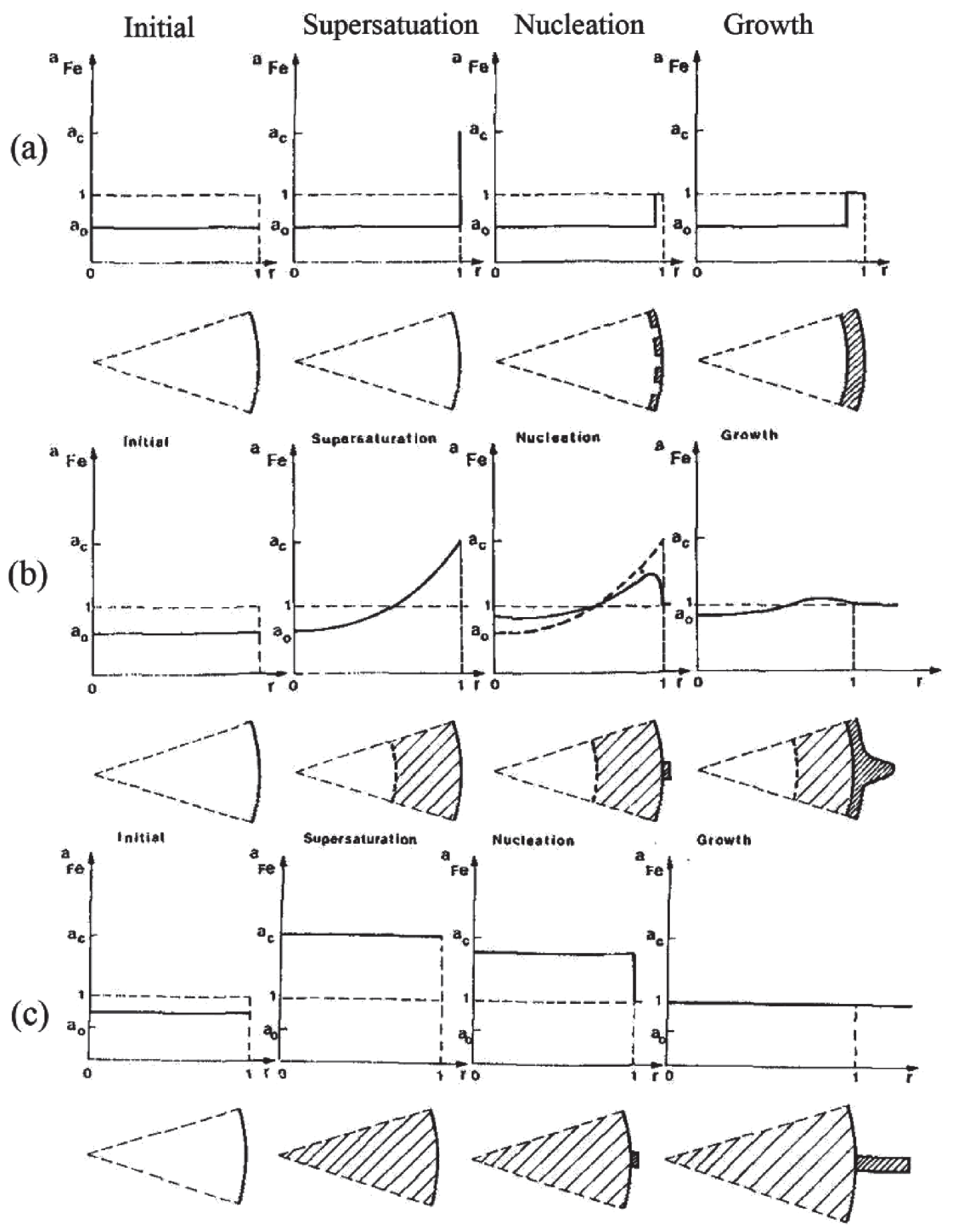

Fig. 4. Schematic diagram of iron atom activity change and particle morphology evolution during the reduction of wustite. $^{50)}$

the iron atoms can diffuse to the center of the ore particles, and the whole particles are like a reservoir for storing iron atoms. The free energy is basically the same throughout the particles. The free energy of the iron atom is gradually increased until the critical nucleation free energy at the surface of the particle (having the lowest critical value of nucleation free energy) is reached, and the iron nuclei begin to form on the surface of the particle. With the continuous supplement of iron atoms in the whole particle, the surface of the ore particles forms some cylindrical whiskers. At the same time, the free energy of the supersaturated iron atoms in the particles returns to the critical value of the chemical reaction, as shown in Fig. 4(c).

$\mathrm{X}$. Z. Gong et al. ${ }^{39)}$ considered that the metallic iron produced by the reduction reaction has a higher binding property than the metallic iron reagent. There are lots of vacancy defects on the surface of an iron whisker, which results in easy iron atom diffusion and lowering its sticking temperature. As shown in Fig. 5.

$\mathrm{Z}$. Du et al. ${ }^{53)}$ investigated the influence of reduction condition on the morphology of newly formed metallic iron. The results reveal that the addition of $\mathrm{H}_{2}$ in $\mathrm{CO}$ accelerates the moving rate of the $\mathrm{Fe} / \mathrm{Fe}_{1-\mathrm{x}} \mathrm{O}$ interface and increases the amount of the iron nucleus formed during the initial reduction period, which induces the transformation of iron morphology from fibrous to dense. The presence of $\mathrm{CO}_{2}$ in $\mathrm{CO}$ makes the fibrous iron shorter and sparser, especially when the content of $\mathrm{CO}_{2}$ is $30 \mathrm{vol} \%$, the iron appears as "cactus-like". D. Neuschütz and S. Hayashi et al. ${ }^{34,54-56)}$ suggest that the sulfur content in the reducing gas has an important influence on the morphology of metallic iron and thus on sticking behavior. Usually the gaseous sulfur 


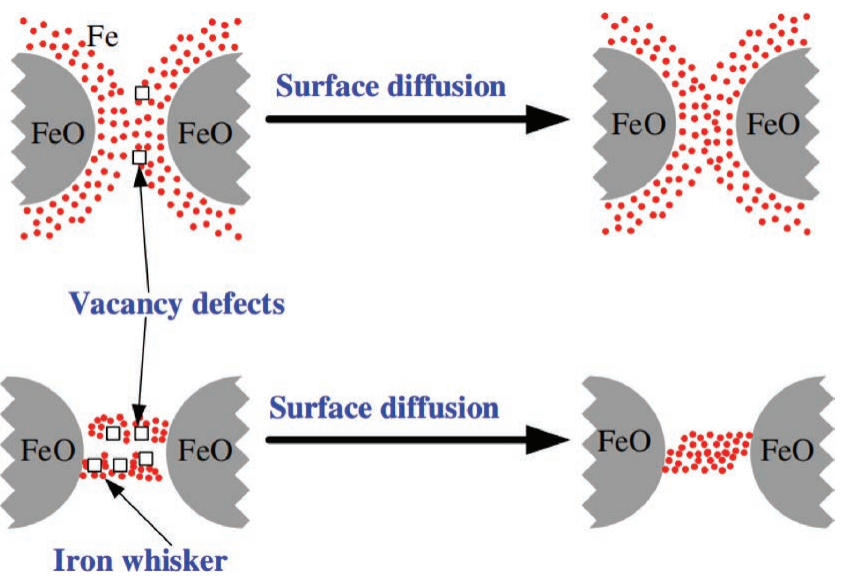

Fig. 5. Sticking mechanism resulting from iron atom diffusion on the surface of an iron whisker. ${ }^{39)}$ (Online version in color.)

is considered to have an effect on promoting the formation of fibrous iron.

L. Feng et al. ${ }^{57)}$ used the phase-field method to study the effect of oxygen content on the growth of iron whiskers, which theoretically proved that the iron whiskers can appear earlier with a low oxygen potential or a high reduction rate. And their findings indicate that the $\mathrm{CO}$ molecule not only has a plane force but also has a force to pull the Fe ion out of the surface, thus supporting the growth of iron whiskers. However, the $\mathrm{H}_{2}$ molecule not only has a strong plane force but also has a force to prevent the growth of iron whiskers. ${ }^{58)}$ It was found that the non-uniform arrangement of fresh iron atoms caused by collision and squeeze of $\mathrm{CO} / \mathrm{CO}_{2}$ molecules is responsible for the formation of iron whiskers. Hence, prevention of iron atoms migration on $\mathrm{FeO}$ (111) surface will prevent the formation of iron whiskers effectively, ${ }^{59)}$ which is in accordance with our consideration: theoretically, metallic iron exists in the form of $\alpha$-iron in the body-centered cubic structure below $1185 \mathrm{~K}$, and its close-packed direction is [111], so the iron whiskers preferentially extend in the [111] direction. $\mathrm{Fe}_{1-\mathrm{x}} \mathrm{O}$ is also in a cubic structure, the iron whiskers grow along the [111] direction of the $\mathrm{Fe}_{1-\mathrm{x}} \mathrm{O}$ lattice. ${ }^{26,60)} \mathrm{L}$. Guo et al. ${ }^{61)}$ proved that the iron whiskers are most likely to exist in single crystal form, and the quantitative relationship between the chemical driving force and the whisker growth is established as $\Delta G^{\theta}+\mathrm{R} T \ln \frac{p_{\mathrm{CO}_{2}}}{p_{\mathrm{CO}}}+2 n \frac{0.056}{r \rho} E_{\mathrm{s}}^{\mathrm{T}}=0$.

\subsection{The Bonding Effect of Highly Active New Metal Iron}

The newly formed metal iron has low crystallinity and high surface energy and viscosity, which can also cause the increase of adhesion and friction force among particles, resulting in the occurrence of de-fluidization. ${ }^{33,38,62)} \mathrm{T}$. Mikami, ${ }^{63)} \mathrm{K}$. Zhu, ${ }^{64)}$ C. F. You, ${ }^{65)}$ B. Zhang ${ }^{66)}$ et al. believe that during the fluidization and reduction of iron ore fines, the surface of the particles will form interconnected solid bridges due to the diffusion of metallic iron, resulting in the interparticle adhesion. Figure 6 shows the bonding state between the two particles due to the newly formed metallic iron on the surface.

Y. W. Zhong et $a .^{43,68)}$ found that the precipitation of metallic iron significantly reduces the sintering temperature

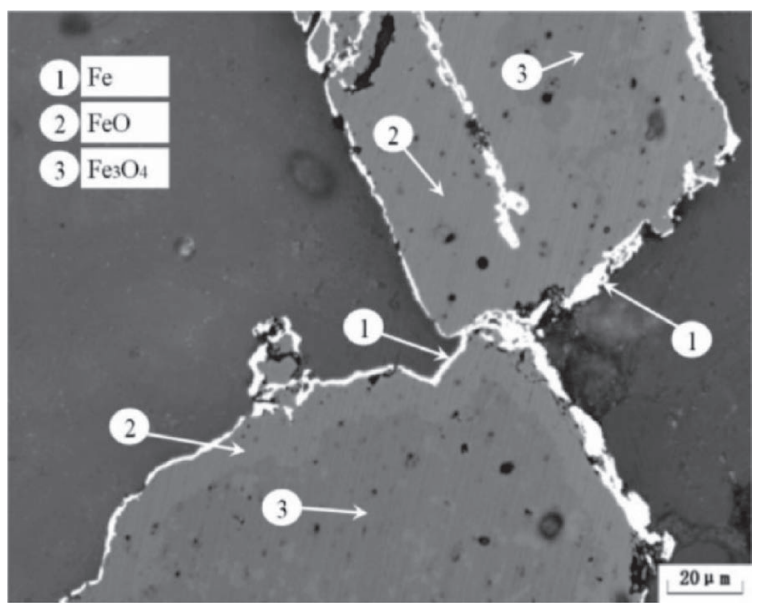

Fig. 6. The sticking phenomenon caused by the newly formed metal iron layer on the surface of the ore particles. ${ }^{67}$

and surface viscosity of $\mathrm{Fe}_{2} \mathrm{O}_{3}$ particles, resulting in the evolution of the bed materials from non-sticky to sticky. Base on the metallic solid bridge theory, L. Guo ${ }^{69)}$ found that the real-time fluidization state can be monitored with the help of electric current acquisition during a fluidized bed reduction of iron ore fines.

\subsection{The Effect of Compounds of Low Melting Point}

When the reduction temperature reaches above 1123 $\mathrm{K}$, the wustite and other gangue components in the ore are prone to produce a liquid phase, ${ }^{38)}$ such as a low-melting eutectic phase similar to $\mathrm{CaO}-\mathrm{SiO}_{2}-\mathrm{FeO}$. These materials tend to soften and bond the particles. ${ }^{33,70)}$ This phenomenon generally occurs after the $\mathrm{FeO}$ phase has been reduced. Softening of the surface of the particles at higher temperatures promotes plastic deformation on the surface of the particles, which increases the contact area during the collision between particles, further promoting the occurrence of bonding phenomena. ${ }^{71)}$

\subsection{The Effect of Van der Waals Force and the Magnetic Attraction}

When the particle or contact point size is below the micron level, the Van der Waals attraction between the particles has reached a degree that can cause them to adhere to each other, but the fine iron ore used in the fluidized bed reduction is generally not such fine, so the effect of Van der Waals force on the sticking problem should be non-existent or very small. ${ }^{33,72,73)}$ When hematite is heated to $873 \mathrm{~K}$, the thermomagnetic residuals are generated, resulting in paramagnetism. The magnetic attraction generated by the magnetized hematite is likely to cause attraction among the particles. For magnetite or hematite iron ore fines, the $\mathrm{Fe}_{3} \mathrm{O}_{4}$ phase produced during the reduction process has a magnetic effect, and its Curie temperature is generally 843-853 K. Above this temperature, the particles are paramagnetic and the attraction effect will be produced. ${ }^{74)}$ However, this phenomenon is also possible only for fine-grained particles.

Among the above explanations for the possible causes of sticking problem in the fluidized bed reduction process of fine iron ore, the most acceptable is the bonding effects of iron whiskers and the highly active new metal iron. 


\section{Influencing Factors of Sticking}

B. G. Langston et al. ${ }^{75)}$ proposed the concept of sticking tendency, which is proportional to the viscosity and contact area between particles, and inversely proportional to particle momentum. It is expressed as the formula:

$$
S_{t}=f\left(\frac{A_{k} S_{p}}{m_{p}}\right)
$$

where $S_{t}$ is the sticking tendency, $A_{k}$ is the contact area between colliding particles $\left(\mathrm{m}^{2}\right), S_{p}$ is the viscosity on the surface of particles $(\mathrm{Pa} \cdot \mathrm{s})$ and $m_{p}$ is the momentum of particles $(\mathrm{kg} \cdot \mathrm{m} / \mathrm{s})$.

More comprehensively, the sticking tendency is a function of particle surface activity, surface viscosity, particle contact area, particle momentum and temperature. ${ }^{75,76)}$ In addition, there are several parameters used to characterize the properties of sticking: (1) Sticking time: S. Hayashi ${ }^{77}$ used the concept of sticking time $\left(t_{\mathrm{s}}\right)$ in his work, which refers to the time from the beginning of fluidization to the a

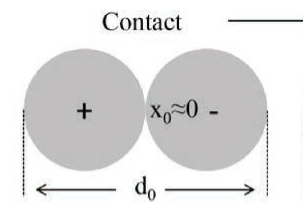

b
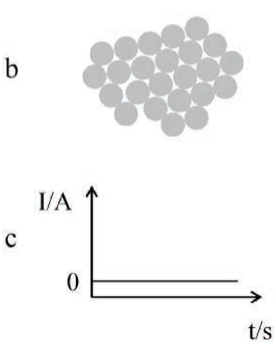
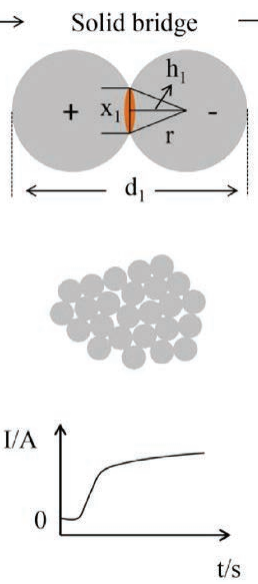

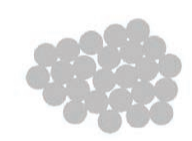

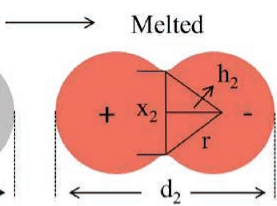
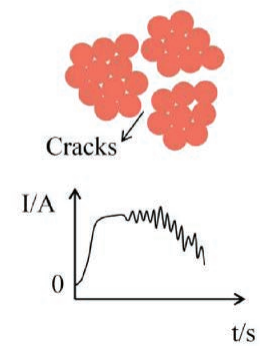

Fig. 7. The conductive mechanism in a fluidized bed (a: micro level; b: macro level; c: corresponding EC curves). ${ }^{69)}$ (Online version in color.) sudden drop of bed pressure. Longer sticking time indicates it less likely to stick. B. Zhang ${ }^{13)}$ defines another concept of sticking time, which refers to the time it takes for a fluidized bed from the beginning of sticking to the end of sticking. This kind of sticking time is usually only a minute or two. The shorter this sticking time is, the easier to stick. (2) Sticking temperature: The lowest temperature at which sticking occurs when other conditions are fixed. The higher the sticking temperature is, the less likely it is to stick. ${ }^{38,78)}$ (3) Sticking index:

$$
S=\frac{W_{1}}{W_{2}} \times 100 \%
$$

where $S$ is the sticking index, $W_{1}$-is the amount of sample larger than the original particle size $(\mathrm{g}), W_{2}$ is the total amount of sample (g). This index is defined by K. S. Zhu et al. ${ }^{79)}$ Theoretically, the degree of sticking can be clearly indicated by this index. The larger the sticking index is, the more severe the degree of sticking is. However, the sticking problem is not completely caused by the bonding effect among the iron ore particles. The increase of the surface friction of the ore fines during the reduction process can also promote the sticking tendency. As the ore fines that have been bonded together first may also be dispersed after cooling or during discharge, it will cause measurement error for this method.

Based on the force balance, a quantitative model for the fluidization characteristics of iron ore fines was developed by Y. W. Zhong et al. ${ }^{80)}$ to describe de-fluidization behavior at elevated temperatures.

Y. L. Zhang et al. ${ }^{81-83)}$ systematically studied the apparent viscosity of iron powders in a fluidized bed using a powder apparent viscosity measurement system (Fig. 8), and defined the specific calculation formula. The concept of the apparent viscosity of powder particles was proposed. Based on the principle of energy dissipation, the method for determining the apparent viscosity of powder particles was determined. The effects of particle size, temperature and additive factors on the apparent viscosity of powder particles were analyzed.

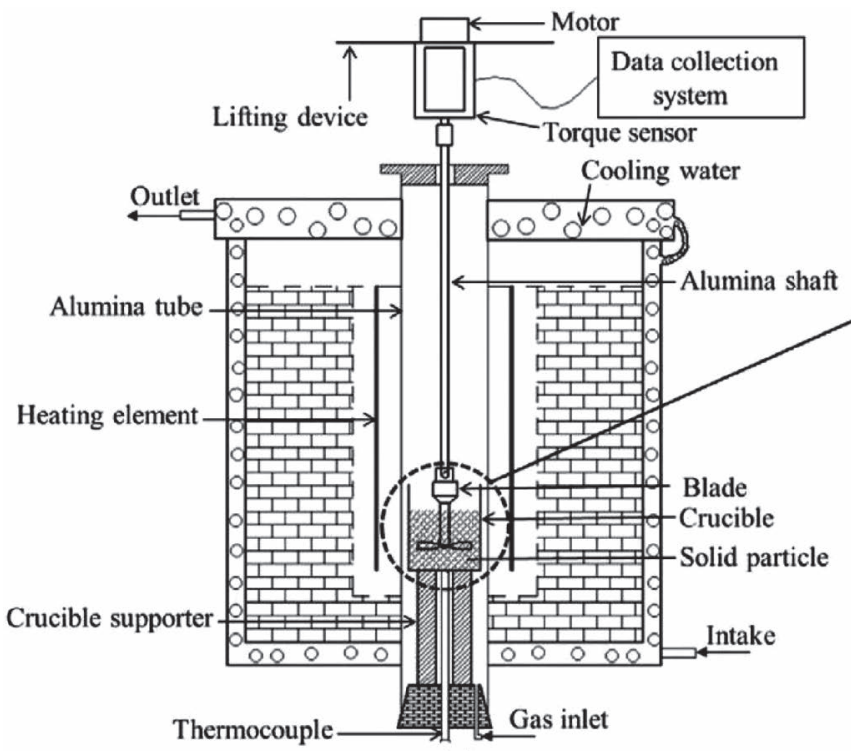

(a)

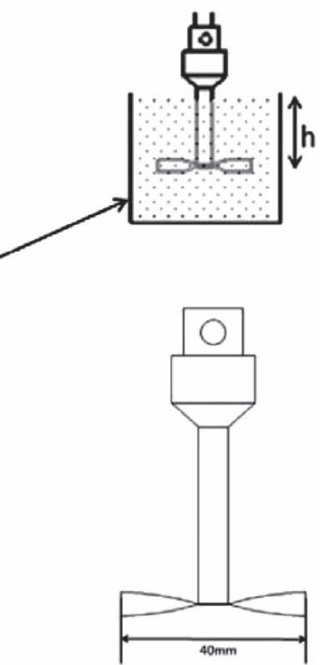

(b)

Fig. 8. Schematic diagram of rotational viscometers (a) and the blade (b). ${ }^{83)}$ 
A positive correlation between the apparent viscosity of the iron powders and the sticking tendency was confirmed. The following relationship was obtained:

$$
\eta=\mathrm{A} \cdot \frac{T}{\pi N_{\mathrm{r}} D}
$$

Where $\eta$ is the apparent viscosity of powder particles $(\mathrm{Pa} \cdot \mathrm{s})$, $T$ is the torque $(\mathrm{N} \cdot \mathrm{m}), N_{\mathrm{r}}$ is the rotation speed $\left(\mathrm{s}^{-1}\right), D$ is the diameter of blades $(\mathrm{m})$ and $\mathrm{A}$ is a constant which depends on the shape of blades.

The most important factors affecting the sticking problem and their mechanisms are as follows:

\subsection{Temperature}

When other conditions are fixed, the sticking of the iron ore fines only occurs above a certain temperature. ${ }^{84)}$ When other conditions change, the critical temperature will also change. ${ }^{85}$ In the actual measurement, this critical sticking temperature is not fixed but fluctuates within a certain range. In order to reduce the sticking tendency, the method of lowering the reduction temperature is usually employed, but this is generally considered to cause a decrease in the rate of the reduction reaction, which is disadvantageous for improving production efficiency. M. S. Guo et al. ${ }^{6}$ have pointed out that the reduction rate of iron ore fines in gas-based fluidized reduction is not simply increased with the increase of temperature because the temperature will affect the morphology of the reduced ore particles. Different morphologies of the ore particles have different effects on the gas diffusion, which affects the rate of reduction. Y. $\mathrm{H}$. Lin et al. ${ }^{86)}$ studied the self-wrapping phenomenon in the reduction process of iron ore fines by using a gas-based micro-fluidized bed, and pointed out that the reduction effect by the low-temperature pre-reduction cooperated with the high-temperature final reduction is better than the one-time high-temperature reduction.

\subsection{Metallization Ratio}

The sticking of the ore fines during the reduction process usually occurs after the emerging of metallic iron and at a certain metallization ratio, which also provides evidence that the iron whiskers and the newly formed metallic iron cause the sticking problem. For a specific kind of iron ore fines, the metallization ratio at the sticking point is fixed within a specific range under constant temperature, reducing gas concentration, gas flow rate and so on. This is because the higher the metallization ratio is, the greater amount of iron whiskers and newly formed iron is, resulting in the sticking problem after the metallization rate reaches a certain level. ${ }^{34,38)}$

\subsection{Gas Flow Rate}

The greater the flow rate of the reducing gas flow is, the greater the agitation effect of the bed layer is, the more intense the collision among the ore particles is, and the shorter the contact time is. So the higher the gas velocity is, the lower the sticking tendency is. The appropriate increase of the flow rate under the premise of ensuring normal fluidization can play a role in suppressing the sticking problem, but at the same time, it will reduce the primary utilization rate of the reducing gas.

\subsection{Reducing Atmosphere}

J. H. Shao ${ }^{87)}$ found in his research that there is a linear relationship between the fluidization time and the reciprocal of the concentration of reducing gas when other conditions are constant, and the metallization ratio at the time of de-fluidization happens usually remains stable. Different kinds of reducing gases and different reducing gas concentrations will affect the precipitation morphology of metallic iron on the surface of the ore fines. Different morphologies of ore fines will affect the sticking tendency, so the reducing atmosphere will also affect the sticking behavior of iron ore fines indirectly. ${ }^{88-90)}$ Due to the presence of the boudouard reaction $\left(2 \mathrm{CO}=\mathrm{CO}_{2}+\mathrm{C}\right)$, the $\mathrm{CO}$ in the reducing gas causes carbon deposition on the surface of the ore fines under certain conditions. The carbon produced is in two states, such as the graphitic carbon and the carbon in $\mathrm{Fe}_{3} \mathrm{C}{ }^{91)}$ It is generally considered that the carbon deposited on the surface of the ore fines has a physical separation effect and can suppress the sticking problem. However, it has also been considered that carburization will cause a decrease in the melting point of metallic iron, which leads to more serious sticking. ${ }^{92)}$

\subsection{Iron Ore Characteristic}

The iron ore characteristics associated with the sticking tendency during the reduction process mainly include ore grade, ore particle size, ore particle shape and so on. The gangue composition in the ore tends to inhibit sticking with respect to metallic iron. The higher ore grade and the less gangue content are, the easier it is to stick. The smaller ore particle size corresponds to the larger specific surface area, the greater contact area between particles, the smaller momentum imparted by the gas flow and the higher sticking tendency. ${ }^{33,63,93)}$ Due to the different frictional forces between particles of different shapes, ${ }^{34)}$ the shape (such as angular and rounded) of the particles will also have different effects on the sticking tendency of the ore fines. ${ }^{94)}$ G. L. Yin ${ }^{95,96)}$ measured the repose angle, collapse angle, dispersion degree, loose density, tap density, fluidity and other physical parameters of different kinds of iron ore fines. The relationship between the physical properties of iron ore fines and the fluidity was systematically evaluated by the degree of compression method, Hausner method ${ }^{97)}$ and the counting method.

Y. W. Zhong et al. ${ }^{98)}$ studied the effects of the particle size distribution (narrow, Gaussian, binary and flat) on the high-temperature de-fluidization behavior and fluidization characteristic of iron powders. And found that the particle adhesion of bed materials was dependent strongly on particle size distribution. Moreover, a thermodynamic model was developed to associate the sticking tendency with the inherent properties of bed materials by the employment of solid surface energy of metallic iron. ${ }^{99)}$

\section{The Solution to the Sticking Problem}

Although the mechanism of the sticking problem has not been clearly explained so far, it does not affect the scholars' research on how to prevent it. At present, the methods for suppressing the sticking problem are mainly divided into the following aspects. 


\subsection{Proper Lowering of the Reduction Temperature}

The temperature plays a decisive role in the sticking of the ore fines, and the sticking phenomenon occurs only at a high reduction temperature, so lowering the reduction temperature can significantly inhibit the sticking problem. The reduction temperature of the main fluidized bed reduction ironmaking equipments in the world is mostly controlled below $1073 \mathrm{~K}$, and the reduction temperature in laboratory tests can sometimes reach $1123 \mathrm{~K}-1173 \mathrm{~K}$. However, reducing the reduction temperature reduces the rate of the reduction reaction, resulting in a decrease in the fluidized bed utilization factor and gas utilization. Increasing the work pressure can make up for the decrease in the reaction rate caused by the temperature decrease. The gas pressure of the industrial fluidized bed ironmaking device is generally 2-6 atmospheres. However, the increase in work pressure will also cause the increase of construction and operating costs.

\subsection{Coating Treatment and Isolation Treatment}

The main functions of the sticking inhibitor are: (1) affecting the precipitation behavior of metal iron, controlling the surface properties and morphology of the particles; (2) isolating the ore fines, and reducing the frequency of contact among particles.

Z. L. Zhao et al. ${ }^{100-103)}$ studied the morphology evolution during $\mathrm{CO}$ gas reduction of $\mathrm{Fe}_{2} \mathrm{O}_{3}$ with an in-situ online observation system composed of an optical stereo microscope and a high temperature hot stage. The effects of $\mathrm{CaO}, \mathrm{MgO}$, alkali metal oxides, et al. on the formation and growth characteristics of iron whiskers during the reduction process were studied and the mechanism was analyzed. The experimental results showed that the iron whiskers formed and continuously grew during the conversion of $\mathrm{FeO}$ to $\mathrm{Fe}$, the $\mathrm{CaO}$ and $\mathrm{MgO}$ have an inhibitory effect on the reduction of iron oxide. When the mass fraction of $\mathrm{CaO}$ is above $8 \mathrm{wt} \%$ and the mass fraction of $\mathrm{MgO}$ is above $2 \mathrm{wt} \%$, no iron whiskers formed. The relationship among the minimum doping amount of alkali earth metal oxides to suppress the growth of iron whiskers $\left(N_{\mathrm{A}_{y} \mathrm{O}_{x}}\right)$, the ionic radius $\left(r_{\mathrm{A}^{x+}}\right)$, the electron layer number $\left(n_{\mathrm{A}^{x+}}\right)$ and the valence electron number $\left(f_{\mathrm{q}}\right)$ was proposed in his study: ${ }^{104)}$

$$
N_{\mathrm{A}_{y} \mathrm{O}_{x}}=1.3 \times 10^{-5} \times \frac{r_{\mathrm{A}^{x+}}^{2} \times \sqrt{n_{\mathrm{A}^{x+}}}}{f_{\mathrm{q}}}
$$

M. S. Guo et al. ${ }^{6}$ have tried to uniformly mix the Panzhihua vanadium-titanium magnetite ore fines with liquid sucrose, $\mathrm{MgSO}_{4} \cdot 10 \mathrm{H}_{2} \mathrm{O}$ aqueous solution or pulp waste liquid, after being dried and calcined it can guarantee 120 mins of fluidization with $\mathrm{H}_{2}$ at $1173 \mathrm{~K}$, during which the fluidized bed maintaines a dense phase fluidization, and the pulp waste liquid also promotes the reaction speed. J. H. Shao ${ }^{67)}$ tried the powder method and solution method to coat $\mathrm{MgO}$. L. Guo ${ }^{105)}$ found that coated calcium phosphate can inhibit the growth of iron whiskers during the reduction of Brazilian ore fines, but does not prevent the sticking problems.

U. F. Chinje et al. ${ }^{106,107)}$ found that the use of C, SiC, $\mathrm{ZrO}_{2}$, et al. as a coating agent has a certain effect on preventing the sticking problem. S. Hayashi ${ }^{108)}$ studied the reduction of hematite in the fluidized bed with $\mathrm{H}_{2}-\mathrm{CO}$ mixed gas containing $\mathrm{H}_{2} \mathrm{~S}$, and finally obtained $\mathrm{Fe}_{3} \mathrm{C}$ product. The experiment prevented the sticking problem by forming $\mathrm{Fe}_{\mathrm{x}} \mathrm{C}$ with $\mathrm{C}$ and $\mathrm{Fe} . \mathrm{K}$. Q. Zhu et al. ${ }^{79,109-111)}$ also studied the use of $\mathrm{CO}$ to precipitate carbon on the surface of the ore fines and then carried out fluidized reduction experiments. The Exxon Corporation of the United States studied the use of alkali metal oxides, alkaline earth metal oxides, hydroxide, carbonate, halide, $\mathrm{MgO}, \mathrm{CaO}$, et al. to prevent the sticking problem with solution method. ${ }^{90,112)} \mathrm{J}$. F. Gransden ${ }^{36}$ ) found that $\mathrm{Al}_{2} \mathrm{O}_{3}, \mathrm{MgO}, \mathrm{SiO}_{2}, \mathrm{CaO}, \mathrm{MnO}$, $\mathrm{TiO}_{2}$, et al. can be applied as coating agents on the surface of the ore fines. And $\mathrm{SiO}_{2}$ shows the best effect, which is believed that $\mathrm{SiO}_{2}$ can penetrate into the lattice of the ferrite to inhibit the reduction of wustite and inhibits the formation of metallic iron on the surface of the ore fines and avoids the occurrence of sticking.

Z. Du et al. ${ }^{113)}$ indicated that the inhibiting effect of $\mathrm{MgO}$ powder on de-fluidization is mainly realized by the physical barrier effect for all iron oxides below $1073 \mathrm{~K}$, while the de-fluidization prevention of $\mathrm{Fe}_{3} \mathrm{O}_{4}$ and $\mathrm{FeO}$ at $1173 \mathrm{~K}$ is mainly attributed to the formation of $\mathrm{Fe}_{2} \mathrm{MgO}_{4}$ and $\mathrm{MgO} \cdot \mathrm{FeO}$ compounds on the surface, respectively. And due to the defects of non-stoichiometry, the reactivity between $\mathrm{FeO}$ and $\mathrm{MgO}$ is higher and the addition of $\mathrm{MgO}$ at the $\mathrm{FeO}$ stage will be more effective in preventing de-fluidization. This is consistent with our study: ${ }^{14,115)}$ the mechanism of prevention of sticking by coating $\mathrm{MgO}$ below $1073 \mathrm{~K}$ is mainly physical isolation. At higher temperatures above $1173 \mathrm{~K}$, the chemical adsorption will occur and the magnesium ferric will appear, which is converted to magnesium iron spinel during reduction. ${ }^{116)}$ Due to the stability of the spinel crystal structure, it is not easily reduced, so it is adsorbed on the surface of the ore fines as a barrier to avoid sticking. The chemical adsorption is more effective than the physical adsorption. The practical application should focus on increasing the proportion of chemical adsorption. The adsorption mechanism is displayed in Fig. 9.

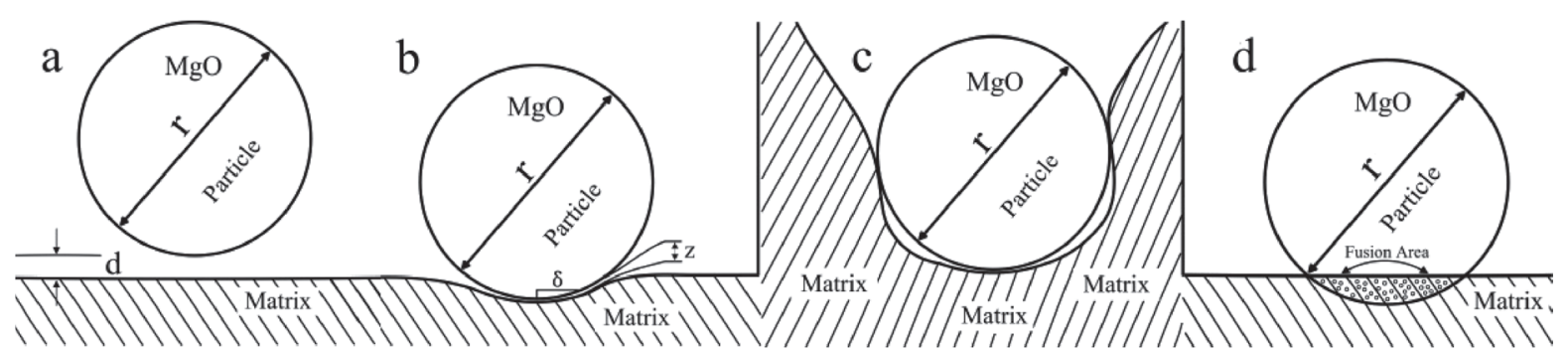

Fig. 9. Adsorption forms of coating particles on the surface of ore fines: bc: physical adsorption; d: chemical adsorption. $^{115)}$ 
L. Guo ${ }^{117,118)}$ tried some coating methods such as the powder method, the slurry method, the on-line coating method, and the co-deposition method. If the metallization ratio of the obtained product is used as the criterion, it is found that the order of several coating methods from good to bad is: the co-deposition method, the online method, the powder method and the slurry method. The adhesion of the fine coating particles on the surface of the ore fines directly determines the coating effect. Q. $\mathrm{Li}^{\left.1{ }^{19}\right)}$ studied the adsorption model of microparticles through the Van der Waals force and capillary force on rough and smooth surfaces. And he pointed out the factors affecting the adhesion of microparticles on the solid surface. M. B. Ranade ${ }^{120)}$ studied the quantitative calculation of the capillary force between the microparticles and the interface, which has reference value when there is liquid phase or softening phase existing on the ore fine surface. A. N. Davis et al. ${ }^{121,122)}$ studied the factors affecting the adhesion between microparticles and solid interfaces (ex. solid contact surface structure, microparticle size et al.).

D. Zhan ${ }^{113)}$ and L. Guo ${ }^{123)}$ both studied the diffusion kinetics during solid state reaction between iron oxide and magnesium oxide, and obtained their respective values of diffusion activation energies. H. Fukuyama et al. ${ }^{124)}$ investigated the solid-state reaction kinetics of the system of $\mathrm{CaO}-\mathrm{FeO}$. J. L. Li et al. ${ }^{125)}$ carried out the simulation of the reduction of ferrite, the ferrite after doping $\mathrm{Mg}^{2+}$ or $\mathrm{Ca}^{2+}$ and the ferrite after carbon deposition treatment using the first principle of density functional theory, and the effect of the above methods on suppressing the generation of iron whiskers was confirmed from the aspect of atomic migration.

M. K. Sesen ${ }^{126)}$ thinks that the addition of $\mathrm{CaO}$ is efficient in promoting the formation and the growth of fibrous iron during reduction of iron oxide. A similar conclusion was drawn by T. Elkasabgy: ${ }^{127}$ he indicates that both calcia and magnesia enhance the kinetics of metallization of wustite and calcia promotes the formation of iron whiskers while magnesia dose not. So it is generally believed that the effect of coating calcium oxide on inhibiting the sticking problem is not as good as that of coating magnesium oxide. Usually the calcia-based additives coated on the surface of iron ore fines show poor prevention performance. Z. Du et al. ${ }^{128)}$ found that the de-fluidization prevention effect of $\mathrm{CaO}$ can be enhanced with $\mathrm{Fe}_{2} \mathrm{O}_{3}$. The product of $2 \mathrm{CaO} \cdot \mathrm{Fe}_{2} \mathrm{O}_{3}$ can restrain the sharp-pointed whisker growth, and $\mathrm{Fe}_{2} \mathrm{O}_{3}$ can improve the adhesive ability of calcia on the surface of sticky iron, thereby decreasing its adhesiveness. As shown in Fig. 10.

In the reduction study of cobalt ferrite by $\mathrm{M}$. Chang et al., ${ }^{129)}$ it was found that $\mathrm{Ca}$ and $\mathrm{K}$ elements promote metal nucleation. Impurities such as $\mathrm{Ca}$ and $\mathrm{K}$ stimulate metal nucleation but appear to inhibit the catalysis of gas-solid reactions at the metal/gas/oxide triple junction and lead to small whisker diameters. N. Shigematsu ${ }^{130)}$ found that the reduction rate is affected significantly by oxides dissolved in $\mathrm{FeO}$ phase and slightly by composite oxides. The coating treatment dose little influence on the reduction kinetics.

\subsection{Carbon Deposition on the Surface of Ore Fines}

It is found that due to the chemical adsorption of $\mathrm{CO}$, an

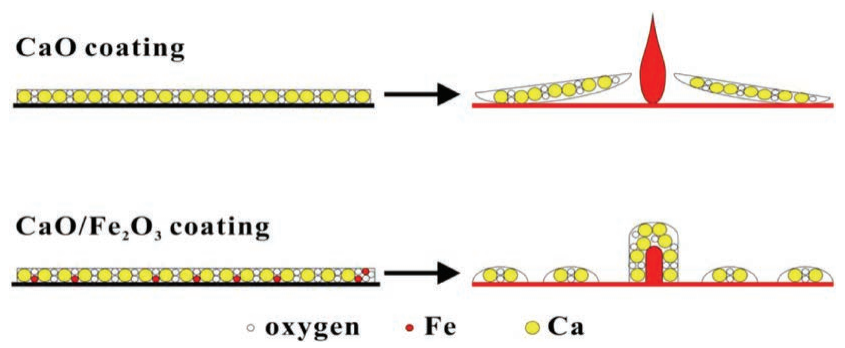

Fig. 10. Schematic diagram of the functional mechanism of $\mathrm{CaO} /$ $\mathrm{Fe}_{2} \mathrm{O}_{3}$ for de-fluidization prevention. ${ }^{128)}$ (Online version in color.)

inert coating of $\mathrm{C}$ or $\mathrm{Fe}_{3} \mathrm{C}$ will form on the surface of iron ore particles, which can prevent the iron-iron contact and thus inhibit the de-fluidization. ${ }^{131)}$ However, in general, the amount of carbon coating that achieves the suppression of sticking problem is over $5 \%$ by weight, ${ }^{111,132,133)}$ and even more than $10 \%$ by weight. ${ }^{91)}$ Excessive carbon deposition is likely to cause an increase in the amount of dust in production, and is not conducive to the subsequent treatment of DRI products. Appropriately increasing the hydrogen content in the carbon pre-reduction gas can increase the metallization ratio of pre-reduction and reduce the carbon content, and make the deposited carbon unstable, ${ }^{133)}$ but can obtain a better final reduction to prevent the sticking problem. ${ }^{134)}$ The detailed reason for this phenomenon is analyzed in section 4.8.2.

C. Lei et al. ${ }^{135,136)}$ found that $1.52 \mathrm{wt} \%$ of carbon coating can prevent the sticking problem of metal iron particles at $1073 \mathrm{~K}$, but for the ore fines, the critical value of deposited carbon at $1173 \mathrm{~K}$ is almost three times of that at 1073 $\mathrm{K} .{ }^{133)} \mathrm{K}$. S. Zhu and others proposed the smelting reduction process of "carbon precipitation $\rightarrow$ fluidization reduction $\rightarrow$ iron bath", ${ }^{137)}$ and carried out the material and heat balance calculations. The carbon coating can not only suppress the sticking problem, but also speed up the reduction. This is because the carbon attached to the surface of the ore fines has the reducing capacity, and has a strong ability to adsorb $\mathrm{CO}_{2}$. The generated $\mathrm{CO}$ gas increases the concentration of the reducing agent, further accelerates the reduction reaction and plays a unique catalytic reduction role. ${ }^{138)} \mathrm{K}$. S. Zhu et al. ${ }^{110)}$ determined that the optimal carbon deposition content for fluidized bed reduction of iron ore fines as a pre-reduction process is about $3 \mathrm{wt} \%$. And the mechanism of carbon deposition reaction in the process of iron ore fines reduction was analyzed. ${ }^{139)}$ The carbon deposition reaction catalyzed by newly formed metal iron can be expressed as:

$$
\begin{array}{r}
\mathrm{Fe}+\mathrm{CO}=\mathrm{Fe} \cdot \mathrm{CO}_{\text {adsorption }} \ldots \ldots \ldots \ldots \ldots . . . . . .(4-2) \\
\mathrm{Fe} \cdot \mathrm{CO}_{\text {adsorption }}+\mathrm{CO}=\mathrm{Fe} \cdot \mathrm{C}_{\text {adsorption }}+\mathrm{CO}_{2} \ldots \ldots .(4-3) \\
\mathrm{Fe} \cdot \mathrm{C}_{\text {adsorption }}=\mathrm{Fe}+\mathrm{C}_{\text {graphite }} \ldots \ldots \ldots \ldots \ldots . . .(4-4)
\end{array}
$$

The newly formed metallic iron produced by reduction has high activity, and the distance between iron atoms $(2.50 \AA$ or $2.86 \AA$ ) at the lattice point is more than doubled than the $\mathrm{CO}$ atom spacing $(1.15 \AA)$ in the $\mathrm{CO}$ molecule, so that the molecular bonds of the adsorbed $\mathrm{CO}$ molecules are loosened and cleaved into $\mathrm{C}$ and $\mathrm{CO}_{2}$. The precipitated graphite carbon atom becomes larger in volume, causing the ore fines 
to crack. The model is shown in Fig. 11.

In terms of coating method of carbon, Q. Y. Xu et $a l .{ }^{140,141)}$ investigated the pressurized carbon deposition from $\mathrm{CO}$ and the carbon coating by pyrolysis of waste plastics. In T. Zhang's study, ${ }^{142}$ a fluidized bed direct reduction process for fine iron ore is proposed, and it contains two steps: (1) constructing the direct reduction particles by $\mathrm{H}_{2}-\mathrm{CO}$ mixture at the temperature lower than 873-948 K, and (2) further reducing the direct reduction particles at the temperature higher than about $1073 \mathrm{~K}$ to obtain high metallization ratios. For step (1), the presence of $\mathrm{H}_{2}$ can retard the growth of iron whiskers and promote carbon deposition. And for step (2), the growth of iron and carbon gasification can destroy the carbon shells, but the presence of CO can retard or prevent the destroying. The detailed operation process is shown in Fig. 12.

\subsection{Isolation Treatment}

J. Fang, ${ }^{12,143,144)}$ Z. M. Zeng, ${ }^{145)}$ L. J. Fan, ${ }^{146-148)}$ R. Huque $^{149)}$ and others used the coal-ore mixed fluidized bed to carry out the fluidized reduction of iron ore fines, the fluidizing gases included $\mathrm{CO}, \mathrm{N}_{2}$ and air. On the one hand, the pulverized coal or coke powder help coating carbon on the surface of the ore particles, and on the other hand can play the role of isolating the iron ore particles, and these two action mechanisms take effect on preventing the sticking problem. And the addition of pulverized coal can increase the reaction rate and shorten the overall reaction time. The ELRED process uses the coal-ore mixed fluidized bed to preheat and pre-reduce the ore fines.

\subsection{Choosing of Proper Kind of Ore}

Different kinds of ores have different iron grades and gangue types, showing different sticking tendency. It is easy to avoid the sticking problem by using ores with a lower sticking tendency. ${ }^{150)}$ Complex paragenic iron ore, which usually contains more gangue phase, is less prone to stick. L. Guo ${ }^{105)}$ attempted to mix the high-phosphorus iron ore, the Indonesian sea sand iron ore and other kind of iron ores with low sticking tendency in different proportions with the Brazilian iron ore and the Hualian iron ore that are prone to sticking. It was proved that the method of mixing ore can prevent the sticking problem.

In addition, by adjusting the particle size distribution of the ore fine particles and preparing the fine particles into larger particles by granulation, the sticking tendency can be lowered to some extent. Q. S. Zhu et al. ${ }^{151,152)}$ used the granulation method in the study of fluidized reduction of ultrafine iron oxide powder. And the synthesis of iron nanoparticles by the reduction of iron oxide nanoparticles in a fluidized bed was achieved, using the self-agglomeration treatment to prevent the de-fluidization.

\subsection{Increase of Fluidization Speed}

Properly increasing the fluidizing gas velocity within the gas velocity range of the bubbling fluidized bed can delay the sticking problem. It is also possible to carry out fluidized reduction using a circulating fluidized bed that exceeds the particle escape velocity. N. S. Srinivasan ${ }^{153)}$ and others have studied the circulating fluidized bed reduction of iron ore fines and found that this method has obvious effects in preventing the sticking problem. However, at the same time, the contact time between the particles and the gas is

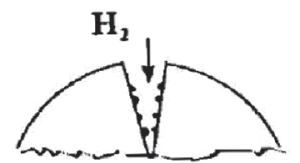

(a) Penetration of $\mathrm{H}_{2}$ and formation of metal iron as a catalyst

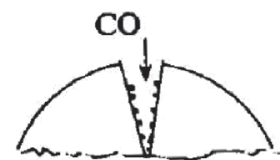

(b) Penetration and absorbtion of $\mathrm{CO}$

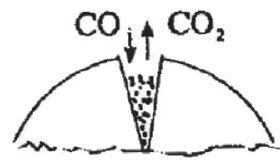

(c) Pyrolysis of $\mathrm{CO}$ and deposition of $\mathrm{C}$

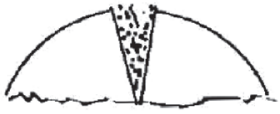

(d) Cracking of iron ore particles

Fig. 11. Schematic diagram of the carbon deposition reaction and ore fine cracking behavior catalyzed by the newly formed metal iron. ${ }^{139}$ )

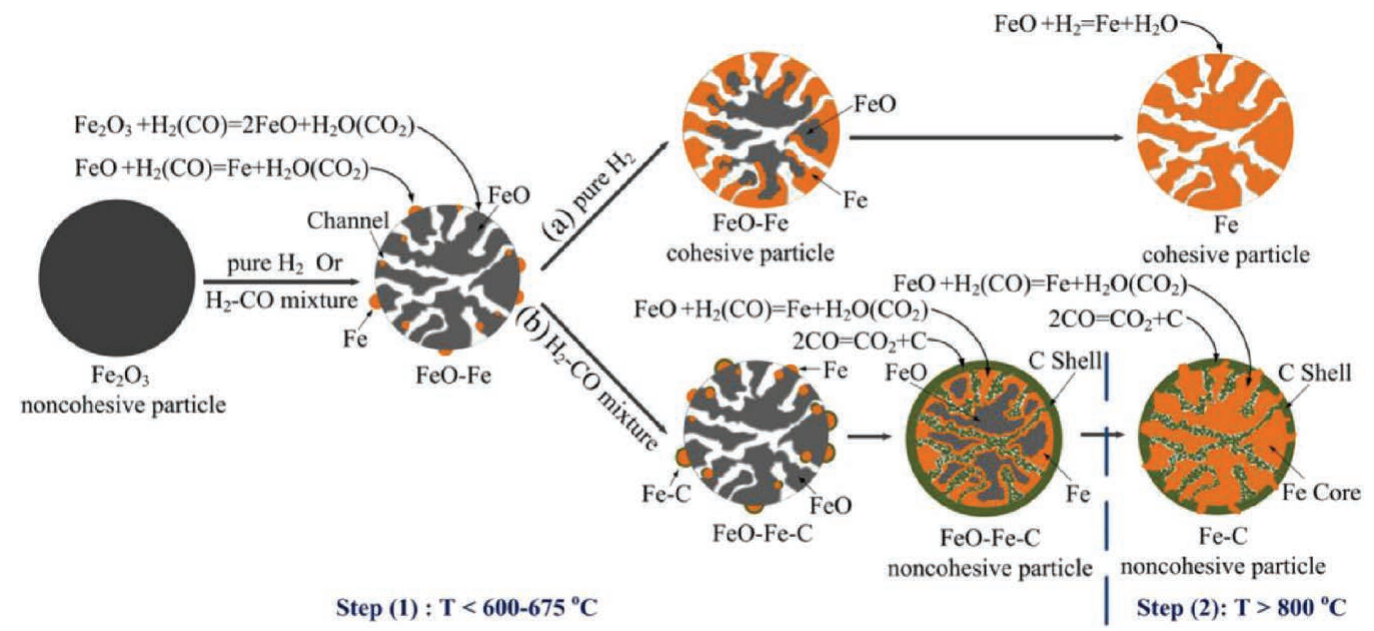

Fig. 12. Diagrammatic sketches of the structure change of an iron ore particle during reduction by (a) $\mathrm{H}_{2}$ and (b) $\mathrm{H}_{2}-\mathrm{CO}$ mixture. $^{142)}$ (Online version in color.) 
shortened, the gas utilization rate is greatly reduced, and the high gas velocity will cause an increase in the operating energy consumption.

\subsection{Stirring and Perturbing}

The mechanical disturbing force can be applied to the particles tending to stick by the external field, thereby increasing the momentum of the particles and preventing the de-fluidization. T. M. Reed ${ }^{154)}$ studied the mechanical agitation effect on the gas fluidization of solids in a small scale rectangular vessel and found that the agitation can be used to advantage to increase the rate of heat transfer between gas and extended surfaces in contact with fluidized beds. Y. F. Song et al. ${ }^{155)}$ introduced the agitation method into the gas-solid fluidized bed and achieved the fluidization and reduction of iron oxide powder with the averaged particle size of $239 \mathrm{~nm}$. X. P. Gu ${ }^{156)}$ studied the bubbling behavior in the agitated fluidized bed with the numerical simulations method based on the computational fluid dynamics.

E. K. Levy ${ }^{157)}$ investigated the combined effects of mechanical and acoustic vibrations on fluidization of cohesive powders. The powders used ranged from normally difficult-to-fluidize fly ash and talc particles with the average diameters of 8 and $15 \mu \mathrm{m}$, to nanoparticles with the diameters of 0.012 and $0.2 \mu \mathrm{m}$. With the introduction of acoustic and mechanical vibrations, the minimum fluidization velocities were reduced to a great extent.

Q. J. Guo, ${ }^{158)}$ C. B. Xu ${ }^{159)}$ and R. D. Morse ${ }^{160)}$ studied the effect of applying sound field to optimize the fluidization state. It is found that the high-frequency sound field can improve the fluidization quality of particles smaller than 30 $\mu \mathrm{m}$ in diameter, and the low-frequency high-intensity sound waves can suppress the channel flow and improve the fluidization performance of the particles. Whereas, the sound field is less effective for the large and dense iron ore fines due to the low agitating energy, so the applicability of this method is limited for the fluidized bed ironmaking process.

\subsection{Control of Particle Structure Evolution}

The sticking of iron ore particles is determined by their surface properties. In addition to using various external methods to prevent the sticking problem, it is also possible to reduce the sticking tendency from the structural evolution of the ore particles themselves.

\subsubsection{Prevention of Iron Whiskers and Promotion of Layered Iron}

The layered iron on the surface of the ore fines has a lower sticking tendency than the iron whiskers. By adjusting the conditions of the reducing atmosphere, temperature and the like, it is possible to suppress the growth of the iron whiskers and promote the effect of crystallization of the metallic iron in the form of layered iron, thereby suppressing the sticking problem.

$\mathrm{Z}$. Du et al. ${ }^{53)}$ found that the addition of $\mathrm{H}_{2}$ in $\mathrm{CO}$ accelerates the moving rate of the $\mathrm{Fe} / \mathrm{Fe}_{1-\mathrm{x}} \mathrm{O}$ interface and increases the amount of the iron nuclei formed during the initial reduction period, which induce the transformation of iron morphology from fibrous to dense shape. And the agglomeration behavior of the fine iron ores could be controlled by pre-reduction in $\mathrm{H}_{2}$-rich reducing gas $\left(\mathrm{H}_{2} / \mathrm{H}_{2}+\right.$
$\mathrm{CO}) \geq 30 \%$, by volume). In order to avoid the de-fluidization of the fluidized bed, Y. H. Qi ${ }^{161)}$ and others used the stepwise reduction method and find that the low-temperature pre-reduction at earlier stage promoted the growth of layered iron, so that the high-temperature reduction at late stage can effectively prevent the sticking problem.

\subsubsection{Promotion of the Porous Morphology}

The porous morphology of the ore fine particles during the reduction process is conducive to the expansion of the reaction interface, thereby increasing the reaction rate and contributing to the internal diffusion of the newly formed metallic iron phase, thereby reducing the accumulation of metallic iron on the surface of the ore fine particles and reducing the sticking tendency.

B. Weiss ${ }^{162)}$ found that during the reduction of iron ore fines the structural changes in particles have a significant influence on the rate of reduction. L. Guo ${ }^{163)}$ found that higher $\mathrm{H}_{2}$ concentrations led to higher metallization ratios, higher speeds of reduction, and higher utilization rates of $\mathrm{H}_{2}$ during the $\mathrm{Fe}_{2} \mathrm{O}_{3}$ particle fluidized reduction process, as shown in Fig. 13. This is because the higher hydrogen concentration contributes to the evolution of the ore fine particles to the porous morphology, thereby increasing the reduction rate and reducing the surface viscosity of the particles. Simultaneously, as the softening of the metallic iron, the forming of a dense metallic iron layer on the surface of the ore fines and the block of the internal diffusion pores caused by the increase in temperature, faster reduction rates and higher metallization ratios were obtained when the reduction temperature decreased from 1273 to $1073 \mathrm{~K}$.

C. Lei et al. ${ }^{134)}$ found that increasing the metallization ratio of the pre-reduced iron ore could reduce the critical carbon content value (the minimum carbon content of iron ore to prevent high-temperature de-fluidization) significantly, as shown in Fig. 14. It is generally believed that the higher the metallization ratio of the ore fines, the more likely the de-fluidization occurs. The above "abnormal" phenomenon displayed in Fig. 14 can be explained by the theory of structure control of ore fines: by increasing the temperature and the $\mathrm{H}_{2}$ mole fraction in the $\mathrm{CO}-\mathrm{H}_{2}$ mixture gas the prereduction rate can be increased and the iron ore particles are prone to form a porous microstructure. The porous structure helps the reduction reaction interface to penetrate into the interior of the particle, thereby reducing the metal iron activ-

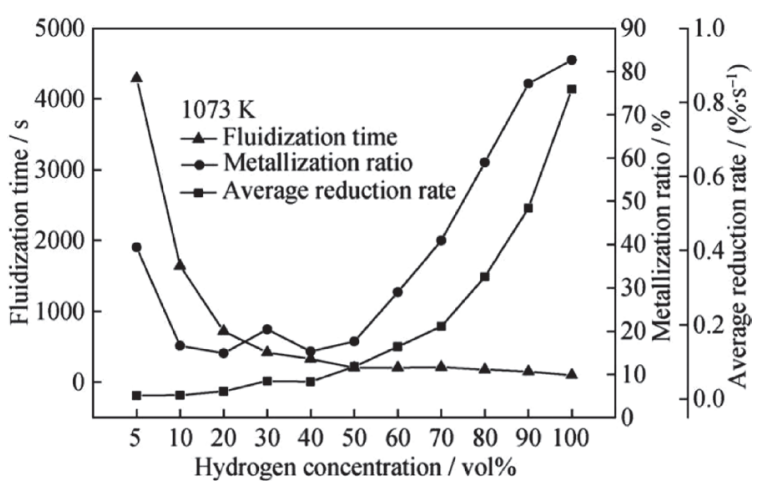

Fig. 13. Experimental results of fluidized bed reduction experiments of $\mathrm{Fe}_{2} \mathrm{O}_{3}$ particles with different hydrogen concentrations under $1073 \mathrm{~K}^{163)}$ 


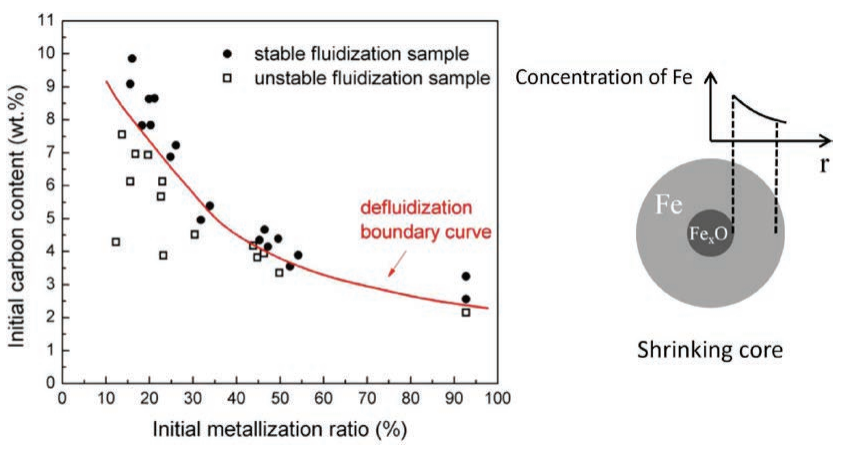

Fig. 14. The fluidization behavior of carbon-coated iron ore fines with different carbon contents and metallization ratios at $1073 \mathrm{~K}$ in $\mathrm{CO}$ atmosphere. ${ }^{134)}$ (Online version in color.)

ity on the surface of the particle and reducing the critical carbon content value.

H. S. Chen et al. ${ }^{164)}$ study the effect of pre-reduction conditions of iron ore fines on the final reduction during fluidized bed reduction with respect to the Finex process, and found that temperature has an important influence on the reduction rate and the product layer structure. The ideal pre-reduction temperature is $973 \mathrm{~K}$. The intrinsic effect of pre-reduction temperature on pre-reduction degree and final reduction degree is the effect of temperature on the reduction rate and product layer structure. On the one hand, the higher the pre-reduction temperature, the faster the chemical reaction rate, the more oxygen loss per unit time, and the more and deeper holes and cracks are formed; on the other hand, the higher the temperature, the faster the sintering rate, the more obvious the sintering effect, thereby causing the compression of holes and cracks and the reduction of porosity. The formation of pores and the sintering of the product layer are progressed simultaneously during reduction, if one is weakened, the other will be enhanced. ${ }^{165,166)}$ The structure of the pre-reduced product layer will have an effect on the final reduction rate and the product structure. On the one hand, the more and deeper holes and cracks in the pre-reduction product layer formed, the easier for the final reducing gas to pass through the product layer reaching the reaction interface, the faster the reaction rate, and the higher the reduction degree. On the other hand, if the pre-reduction product is porous, the sintering in the final reduction stage will be slowed down, and the iron ore fine particles will form a loose porous final reduction product layer.

\subsection{Changing of the Fluidized Form}

The fluidized bed includes various forms such as the bubbling fluidized bed, the circulating fluidized bed, the dropping bed, and the like. The sticking problem usually accompanies with the bubbling fluidized bed. If the form of fluidization is changed, it is possible to fundamentally eliminate the occurrence of sticking of iron ore fines.

\subsubsection{Circulating Fluidized Bed}

The particles in a circulating fluidized bed is fluidized at a gas velocity greater than the free settling velocity. The iron ore fines circulate in the riser and the drop tube and are gradually reduced by the fluidizing gas. Due to the high kinetic energy of the high-speed airflow to the ore fine particles, there is a huge shear force between the particles colliding with each other, so that the problem of sticking between the particles can be avoided. M. S. Chu ${ }^{167,168)}$ conducted a mathematical analysis of the kinetics of direct reduction of iron ore using a circulating fluidized bed.

\subsubsection{Pulsating Fluidized Bed}

By introducing a pulsating gas stream into the fluidized bed, a batch-type fluidization state can be realized. The pulsating airflow can improve the flow in the common fluidized bed, alleviate the sticking tendency of the ore fine particles, and at the same time enhance the heat and mass transfer characteristics of the gas phase and increase the reduction speed. Y. F. Liu ${ }^{169)}$ systematically studied the pulsating fluidized bed combustion technology. W. G. $\mathrm{Su}^{170)}$ studied the pulsating fluidized bed using the numerical simulation method and found that the pulsating gas flow added can initialize bed fluidization at low gas velocity and with the pulsating flow under resonance the fluidized bed quality can be improved and the turbulence of fluidization is enhanced.

\subsubsection{Conical Fluidized Bed}

The conical design at the bottom of the fluidized bed can promote the circulation of the ore fine particles from the center to the wall surface. This method can effectively improve the fluidization state of the common bubbling fluidized bed and reduce the sticking tendency to some extent.

$\mathrm{S}$. Y. He et al. ${ }^{171)}$ found that the de-fluidization can be successfully inhibited without adding inert materials or causing elutriation issues in a conical fluidized bed with a high superficial gas velocity. M. Ozawa ${ }^{172)}$ studied the reduction of iron ore fines using a large cone angle jet fluidized bed and found that the sticking tendency was less compared with the low gas velocity region in a usual fluidized bed.

\subsubsection{Flash Reduction with the Drop Tube Bed}

The flash ironmaking technology (FIT) is a process which can complete the reduction of iron ore fines in a very short period of time. The apparatus used in the process is similar to the drop tube fluidized bed, and the ore fines are in contact with the high-temperature reducing gas and reduced during the falling process. As early as 1971, M. Ozawa ${ }^{173)}$ studied the $\mathrm{H}_{2}$ reduction process of ultrafine iron ore fines in the temperature range of $1023 \mathrm{~K}-1223 \mathrm{~K}$ in a pneumatic conveying device. Also using this pneumatic conveying device, in 1982, F. Tsukihashi ${ }^{174)}$ studied the reduction kinetics of iron oxide particles under the conditions of $1723 \mathrm{~K}$ and $1873 \mathrm{~K}$, and found that the iron oxide particles melted into spherical liquid drops with metallic iron inside and molten wustite phase outside during the reduction process. In 1993, S. Hayashi ${ }^{94175)}$ studied the characteristics and mechanism of the reduction process of wustite particles with $\mathrm{H}_{2}$ at 1723 $\mathrm{K}$ and $1823 \mathrm{~K}$. It was found that the reduction degree of nearly $80 \%$ can be achieved in less than $1 \mathrm{~s}$ in the strong reduction atmosphere. The obtained particles are composed of spherical metal iron inside and unreduced wustite phase covering outside. N. J. Themelis ${ }^{176)}$ introduced a rate equation describing the hydrogen reduction process of iron oxide particles with the particle size range of 70-42 $000 \mu \mathrm{m}$, and pointed out that the effect of temperature on the reduction reaction rate is accomplished through the chemical reaction 
itself and the crystallization of metallic iron indirectly. Y. $\mathrm{K}$. $\mathrm{RaO}^{177)}$ studied the nucleation rate during the reduction process and the effect of the growth mode of the metal iron nucleus on the reduction rate of the ferrite.

N. Takeuchi ${ }^{178)}$ studied the reduction kinetics of spherical $\mathrm{FeO}$ in the temperature range of $1373 \mathrm{~K}-1573 \mathrm{~K}$ with $\mathrm{CH}_{4}$ gas using a drop bed. It is found that the reduction rate is faster than that of using $\mathrm{H}_{2}$. The reason is explained that $\mathrm{H}_{2}$ does not easily diffuse into the reaction interface between $\mathrm{FeO}$ and $\mathrm{Fe}$ when the metal iron layer is formed on the periphery of the particles, and $\mathrm{C}$ which is decomposed by $\mathrm{CH}_{4}$ can penetrate into the metal iron layer and enter the reaction interface. Thus, the reduction speed limit step at this time is the interface chemical reaction.

H. Y. Sohn et al. ${ }^{179-181)}$ conducted hydrogen reduction experiments on iron concentrate particles of about $30 \mu \mathrm{m}$ at

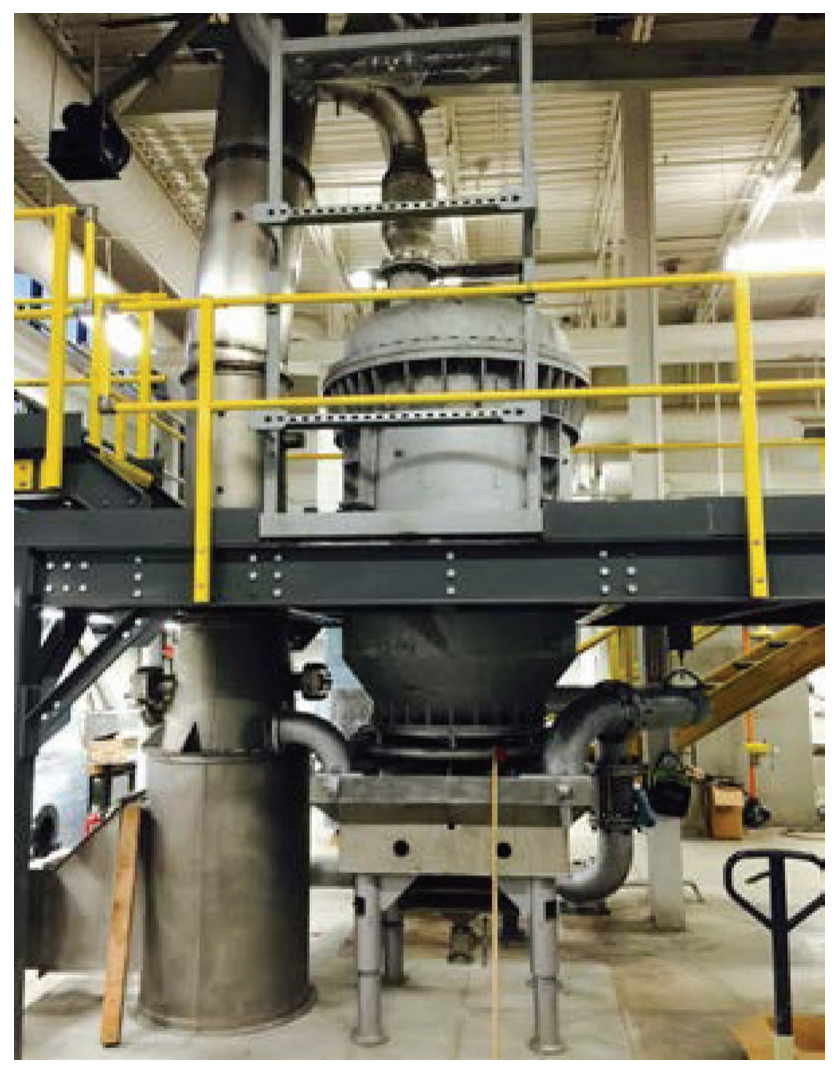

Fig. 15. The picture of a scale-up apparatus for FIT developed in the University of UTAH. (Online version in color.) the temperatures above $1573 \mathrm{~K}$. It was found that the iron ore particles can achieve a reduction degree of $90 \%-99 \%$ in a few seconds. So they put forward the idea of flash ironmaking technology. In addition to its fast rate of reduction, this process can avoid the solid-solid contact effectively during the reduction process and avoid the sticking problems. ${ }^{34,91,182)}$ After 2008, this process was supported by the US Department of Energy and industries for amplification experiments. ${ }^{183)}$ A scale-up apparatus developed in the University of UTAH is displayed in Fig. 15. L. Guo ${ }^{184,185)}$ carried out the flash reduction experiments on $\mathrm{Fe}_{2} \mathrm{O}_{3}$ particles in low temperature range $(873 \mathrm{~K}-1373 \mathrm{~K})$ and high temperature range $(1573 \mathrm{~K}-1873 \mathrm{~K})$ respectively using two kinds of drop bed devices. ${ }^{60)}$ And the morphological evolution characteristics of the particles during reduction at different temperatures are summarized. B. Abolpour ${ }^{186-191)}$ conducted some research on the CFD simulation and reduction kinetics of this process.

\section{Discussion}

There are some misleading concepts in the study of inhibiting the sticking problem. They are analyzed as follows:

(1) To prevent the sticking problem of iron ore fines, measures should be taken from two aspects of reducing the adhesive properties of the ore particles and improving the fluidization conditions. The generation of iron whiskers deteriorates the fluidization state, but the suppression of the presence of iron whiskers does not necessarily achieve the effect of preventing the sticking problem. The iron whisker is only one of the existing forms of the newly formed metallic iron on the surface of ore particles, and layered iron can also cause the sticking problem.

(2) The sticking problem usually happens when a certain metallization ratio is reached. The metallization ratio is an average index, and what really affects the sticking properties is the metal iron concentration on the surface of the ore particle. For the following two phenomena: (a) the internal reduction of the ore particle is sufficient, and there is no much difference on the concentration of metal iron in the interior and the surface layer; (b) the reduction is concentrated on the surface layer of the ore particle, and the internal reduction is insufficient. Under the same metallization ratio, the sticking problem is more prone to happen for condition (b), namely, a higher metallization ratio can be

Table 1. A time line of the relative researches on the FIT.

\begin{tabular}{|c|c|c|c|c|c|c|}
\hline Researchers & Country/Organization & Years & Reductant & Temperature/K & Particle size & Feeding method \\
\hline M. Ozawa & Japan/Institute of Metallic Materials & 1972 & $\mathrm{H}_{2}$ & $1023-1223$ & $5-40 \mu \mathrm{m}$ & Vibrating/Pneumatic transmission \\
\hline F. Tsukihashi & Japan/Tokyo University & 1982 & $\mathrm{CO}$ & $1723-1873$ & $\mathrm{FeO} 5-40 \mu \mathrm{m}$ & Fluidized bed/Pneumatic transmission \\
\hline S. Hayashi & Japan/Nagoya Institute of Technology & 1994-1999 & $\mathrm{CO} \& \mathrm{H}_{2}$ & $1723-1823$ & $\begin{array}{c}\text { Spherical FeO } \\
53-63 \mu \mathrm{m}\end{array}$ & Spiral feeder \\
\hline N. Takeuchi & Japan/Kyushu University & 2005 & $\mathrm{CH}_{4}$ & $1373-1573$ & $\begin{array}{l}\text { Spherica FeO } \\
32-45 \mu \mathrm{m}\end{array}$ & Spiral feeder \\
\hline H. Y. Sohn & USA/University of UTAH & 2010 & $\mathrm{H}_{2}$ & $1473-1773$ & $25-32 \mu \mathrm{m}$ & Vibrating honeycomb \\
\hline Lei Guo & China/USTB & 2016 & $\mathrm{CO} \& \mathrm{H}_{2}$ & $873-1873$ & $10-100 \mu \mathrm{m}$ & Bell-shaped distributer \\
\hline B. Abolpour & Iran/University of Kerman & 2017 & $\begin{array}{c}\mathrm{CO} \& \mathrm{H}_{2} \\
\& \mathrm{CH}_{4}\end{array}$ & $773-1573$ & $0.5-39 \mu \mathrm{m}$ & Screw feeder \\
\hline
\end{tabular}


reached when sticking happens at condition (a). Therefore, it cannot be said simply that the higher the metallization ratio is reached by the ore fines, the more likely the sticking problem occurs.

(3) The prevention of the sticking problem does not mean extending the fluidization time blindly. L. Guo ${ }^{163)}$ found that the normal fluidization time can be prolonged with lower reduction temperature and lower concentration of reducing gas, but the metallization ratio reached by the ore fines after the occurrence of de-fluidization is not very high. And the de-fluidization will occur in a short period of time with higher reduction temperature and higher concentration of reducing gas, but the metallization ratio of the product obtained is high. Therefore, the ultimate goal of suppressing the sticking problem should not be to extend the fluidization time, but to increase the metallization ratio before the happening of de-fluidization.

(4) The inert oxide used in the coating process will not cause the introduction of a large amount of gangue phases. The role of the coating agent is to adsorb on the surface of the ore particle to reduce its sticking tendency, and the thickness of the coating is usually about $1 \mu \mathrm{m}$. The concentration of the gangue phase on the thin layer of the ore particle surface increase greatly due to the coating effect, but for the whole particle, the increase of the gangue phase is very limited, which is usually below $1 \mathrm{wt} \%$.

\section{Prospect of Inhibiting the Sticking Problem}

Table 2 lists the information of some non-blast furnace ironmaking processes related to the fluidized bed uint. In many non-blast furnace ironmaking processes, the fluidized bed is used as the preheating and pre-reduction device of the ore powder. It can be seen that the fluidized bed ironmaking technology plays an important role for the development of non-blast furnace ironmaking, and solving the sticking problem is the key to the further development of this technology.

\subsection{Combination of Multiple Sticking Prevention Methods}

Comparative analyzing of various prevention measures, the coating treatment by mixing inhibitors in iron ore fines is considered to be the most convenient for industrial application. On one hand, this method does not increase the gas flow rate, which can ensure the gas utilization rate; in addition, the added oxide coating agent will become part of the slag phase in the later smelting process, and the added coke or pulverized coal powder can be used as the smelting fuel and the reducing agent, neither will put an extra burden on the entire process.

In addition, various methods can be combined to achieve an optimal effect on the inhibiting of sticking problem. For example, the multistage reduction method and the carbon coating method combined with the particle morphology controlling method.

Table 2. A summary of non-blast furnace ironmaking processes using fluidization technology. ${ }^{12,192-195}$

\begin{tabular}{|c|c|c|c|c|c|c|c|}
\hline $\begin{array}{l}\text { Born } \\
\text { year }\end{array}$ & $\begin{array}{l}\text { Process } \\
\text { name }\end{array}$ & Company & Pre-reduction setup & Reduction gas source & Feeding material & Temperature & Pressure \\
\hline 1950 & H-Iron & $\begin{array}{c}\text { Hydrocarbon } \\
\text { Research Inc. and } \\
\text { Bethlehem Steel Co. }\end{array}$ & 3 stage fluidized bed & $96 \% \mathrm{H}_{2}$, others $\mathrm{N}_{2}$ & - & $813 \mathrm{~K}$ & 27 bar \\
\hline 1962 & FIOR & Exxon & 3 stage fluidized bed & $\begin{array}{c}\text { Combustion gas of natural } \\
\text { gas or coal }\end{array}$ & $\begin{array}{c}\text { Gangue phase }<5 \%, \\
\mathrm{~d}_{\mathrm{p}}<4.7 \mathrm{~mm}, \\
\text { particles }<0.043 \mathrm{~mm} \\
\text { less than } 20 \%\end{array}$ & $973-1073 \mathrm{~K}$ & 10 bar \\
\hline 1968 & NOVALFER & - & 2 stage fluidized bed & Natural gas steam reforming & - & $853-973 \mathrm{~K}$ & - \\
\hline 1976 & ELRED & $\begin{array}{l}\text { Asea and Stora } \\
\text { Kopparberg }\end{array}$ & $\begin{array}{l}\text { Circulating } \\
\text { fluidized bed }\end{array}$ & Non-coking coal & $\begin{array}{c}\text { Magnetic separation } \\
\text { concentrate }\end{array}$ & $1223-1273 \mathrm{~K}$ & 5 bar \\
\hline 1979 & $\begin{array}{l}\text { UN-IRON or } \\
\text { HIB }\end{array}$ & US-Steel Co. & 2 stage fluidized bed & $\begin{array}{c}\text { Water vapor catalytic } \\
\text { cracking }\end{array}$ & $<1.65 \mathrm{~mm}$ & $973-1023 \mathrm{~K}$ & 2 bar \\
\hline 1985 & Circofer & Lurgi & $\begin{array}{l}\text { Circulating } \\
\text { fluidized bed }\end{array}$ & $\begin{array}{c}\text { Combustion gas of natural } \\
\text { gas or coal }\end{array}$ & $0.3 \mathrm{~mm}<\mathrm{d}_{\mathrm{p}}<1 \mathrm{~mm}$ & $<1233 \mathrm{~K}$ & - \\
\hline 1993 & DIOS & Japan steel federation & $\begin{array}{l}\text { Rapid and bubbling } \\
\text { fluidized bed }\end{array}$ & Non-coking coal or coal gas & $<8 \mathrm{~mm}$ & $873-1073 \mathrm{~K}$ & - \\
\hline 1996 & Circored & Lurgi & $\begin{array}{c}\text { Circulating and } \\
\text { bubbling fluidized bed }\end{array}$ & Pyrolysis of natural gas & - & $903-923 \mathrm{~K}$ & 4 bar \\
\hline 2001 & Finmet & BHP and VAI & $\begin{array}{l}4 \text { stage bubbling } \\
\text { fluidized bed }\end{array}$ & Pyrolysis of natural gas & $<12 \mathrm{~mm}$ & $923-1123 \mathrm{~K}$ & 10 bar \\
\hline 2003 & Finex & Posco and VAI & $\begin{array}{c}3 \text { ore } 4 \text { stage Bubbling } \\
\text { fluidized bed }\end{array}$ & Non-coking coal & $<8 \mathrm{~mm}$ & $673-1073 \mathrm{~K}$ & 4 bar \\
\hline 2003 & HIsmelt & $\begin{array}{l}\text { Rio Tinto, Nucor, } \\
\text { Mitsubishi and China } \\
\text { shougang group }\end{array}$ & $\begin{array}{l}1 \text { stage Circulating } \\
\text { fluidized bed }\end{array}$ & Non-coking coal & $<6 \mathrm{~mm}$ & $<1123 \mathrm{~K}$ & Ambient \\
\hline 2004 & FROLTS & $\begin{array}{l}\text { Central iron and steel } \\
\text { research institute of } \\
\text { China }\end{array}$ & $\begin{array}{l}\text { Rapid circulating and } \\
\text { Bubbling fluidized bed }\end{array}$ & Coal combustion gas & $<1 \mathrm{~mm}$ & $973-1023 \mathrm{~K}$ & - \\
\hline
\end{tabular}




\subsection{Hydrogen-based Fluidized Bed Ironmaking}

The blast furnace and other smelting reduction processes use large amounts of carbon-based energy, causing a large amount of greenhouse gas emission each year. The international community's call for curbing global warming has put enormous pressure on the iron and steel industry to save energy. In addition, due to the many advantages of fuel cells, the new energy automotive industry also places great demands on hydrogen energy. In the future, the proportion of hydrogen energy in the energy system will be higher and higher.

The HYBRIT Development, a Swedish joint venture between the SSAB, the state-owned iron ore producer LKAB and the state-owned electric power company Vattenfall, proposed a carbon-free steelmaking process using the electrolytic hydrogen production technology to provide hydrogen gas for the production of direct reduced iron. The United States, China, South Korea and other countries are all deploying the project of hydrogen production with nuclear energy. The nuclear energy hydrogen production technology has the advantages of no greenhouse gases generating, using water as raw materials, high efficiency, large scale, et al. Thus, it is an important solution for large-scale supply of hydrogen in the future. A 600000 $\mathrm{kW}$ high-temperature gas-cooled reactor unit can meet the energy demand of 1.8 million tons of steel production in terms of hydrogen, electricity and part of oxygen, reducing the emission of $\mathrm{CO}_{2}$ by about 3 million tons and reducing the energy consumption by about 1 million tons of standard coal per year.

The use of hydrogen as a reducing agent can not only achieve zero carbon emission, but also help to increase the reaction rate. The fluidized bed ironmaking process directly using the fine iron ore can well cooperate with the hydrogen reduction operation, which helps to exert the technical advantages of hydrogen reduction such as low emission and high efficiency. At the same time, the use of hydrogen as a reducing agent helps to reduce the sticking tendency of the ore fines, which contributes to stable operation. The solution to the problem of hydrogen resources contributes to the implementation of some highly efficient direct reduction ironmaking processes like the flash ironmaking technology.

\section{Conclusions}

(1) The main reason for the occurrence of sticking problem is the accumulation of newly formed metallic iron on the surface of the ore fine particles. The formation of iron whiskers exacerbates the sticking tendency of ore fine pariticles.

(2) Since the newly formed metal iron is the main cause of the sticking problem, the main factors affecting the sticking behavior are usually some factors affecting the properties of the newly formed metal iron.

(3) The most fundamental factor in suppressing the sticking problem is to change the surface properties during the reduction of iron ore fines, thereby reducing the surface viscosity. The dual goal of suppressing the sticking problem and improving the reaction efficiency can be accomplished by taking comprehensive measure from the two aspects: the particle itself and the external conditions.
(4) The fluidized bed ironmaking process has many advantages in terms of reaction efficiency and low cost, which is suitable for many non-blast furnace ironmaking technologies as a mean of pre-reduction. Aided by the solving of sticking problem in actual operation, the fluidized bed ironmaking technology will receive more and more attention nowadays when the carbon and pollutant emissions become more stringent.

\section{Acknowledgments}

This study is supported by the Natural Science Foundation of China (No. 51804030 and No. 51604020), the Key Projects of the State Key Research and Development Plan (No. 2016YFB0601304). The authors would also thank the support of the China Scholarship Council.

\section{REFERENCES}

1) H. Y. Huang and L. X. Zhou: Met. Mater. Metall. Eng., 35 (2007), 49 (in Chinese)

2) X. Q. Cheng and S. J. Liu: Eng. Chem. Metall., 8 (1987), 66 (in Chinese).

3) FINEX-Environmentally Safe Ironmaking, Primetals: https://www. primetals.com/portfolio/ironmaking/finexr/, (accessed 2019-06-24).

4) C. Böhm, D. Siuka, J. L. Schenk and J. Kriechmair: China Steel Annual Meeting, Metallurgical Industry Press, Beijing, (2007), 142.

5) Y. Liu, H. J. Guo, L. Guo, Y. Q. Li and G. Y. Sun: Met. Mine, (2014), No. 9, 43 (in Chinese).

6) R. X. Yang and M. S. Guo: Chin. J. Process Eng., (1980), No. 2, 100 (in Chinese)

7) M. S. Guo: Iron Steel, 14 (1979), 1 (in Chinese)

8) L. Guo, J. T. Gao, Y. W. Zhong, H. Gao and Z. C. Guo: ISIJ Int., 55 (2015), 1806.

9) Q. C. Bu, J. B. Lv, P. F. Li, J. B. Liao and J. H. Ge: China Metall., 26 (2016), 45 (in Chinese)

10) R. Haslehner, B. Stelter and N. Osio: Steel as a model for a sustainable metal industry in 2050, (2015), https://www.bcg.com/ publications/2015/metals-mining-sustainability-steel-as-a-model-fora-sustainable-metal-industry-in-2050.aspx, (accessed 2019-06-24)

11) World Steel Dynamics: World Direct Reduction Statistics, Midrex Technologies, Inc., Charlotte, (2018), 6.

12) J. Fang: Technology and Theory of Non-blast Furnace Ironmaking, Metallurgical Industry Press, Beijing, (2010), 3 (in Chinese).

13) B. Zhang: Ph.D. thesis, University of Science and Technology Beijing, (2013) (in Chinese).

14) M. Shan: Sinter. Pelletizing, (1994), No. 2, 38 (in Chinese)

15) Z. L. Zhao: Ph.D. thesis, University of Science and Technology Beijing, (2012) (in Chinese).

16) G. Deimek: Iron Steel, 35 (2000), 13 (in Chinese).

17) R. H. Whipp and Y. Deng: Sinter. Pelletizing, (1987), No. 2, 68 (in Chinese).

18) S. G. Xu, Z. M. Li and Q. Lv: Bengang Technol., (2007), No. 4, 1 (in Chinese).

19) Y. W. Liu and X. F. Wang: Angang Technol., (2004), No. 3, 16 (in Chinese).

20) B. C. Zhu: Res. Iron Steel, (1998), No. 3, 50 (in Chinese)

21) B. Y. Liu, S. Jia and Z. F. Xi: J. Henan Inst. Sci. Technol., (2013), No. 1, 78 (in Chinese).

22) S. N. Cui and J. C. Yang: Sci. Technol. Inf., (2011), No. 6, 331 (in Chinese).

23) P. G. Zhang, Y. M. Zhang and Z. M. Sun: J. Mater. Sci. Technol., 31 (2015), 675

24) S. S. Brenner and G. W. Sears: Acta Metall., 4 (1956), 268

25) H. T. Wang and H. Y. Sohn: Steel Res. Int., 83 (2012), 903.

26) Y. Iguchi, Y. Uyeda, K. Goto and S. Hayashi: Oxid. Met., 42 (1994), 103 .

27) D. Sciti, L. Pienti, D. D. Fabbriche, S. Guicciardi and L. Silvestroni: Ceram. Int., 40 (2014), 4819.

28) M. Mashhadi, F. Mearaji and M. Tamizifar: Int. J. Refract. Met. Hard Mater., 46 (2014), 181.

29) S. H. Chen, D. F. Zhang, J. Q. Li and G. Sun: Powder Technol., 253 (2014), 677.

30) P. K. Yan, Z. X. Ma and Y. J. Gao: China Non-met. Min. Ind. Her., (2009), No. 3, 23 (in Chinese).

31) M. L. Cao, C. Zhang, H. F. Lv and L. Xu: Constr. Build. Mater., 66 (2014), 89

32) G. Y. Dou: Met. World, (1999), No. 4, 21 (in Chinese).

33) M. Komatina and H. W. Gudenau: Metalurgija, 10 (2004), 309

34) S. Hayashi and Y. Iguchi: ISIJ Int., 32 (1992), 962. 
35) R. Degel: Ph.D. thesis, RWTH Aachen, (1996), https://www.tib. eu/de/suchen/id/TIBKAT\%3A216751136/Eisenerzreduktion-in-derWirbelschicht-mit-wasserstoffreichem/, (accessed 2019-09-12).

36) J. F. Gransden and J. S. Sheasbu: Can. Metall. Q., 13 (1974), 649.

37) P. L. M. Wong, M. J. Kim and H. S. Kim: Ironmaking Steelmaking, 26 (1999), 53

38) J. Fang: Iron Steel, 26 (1991), 11 (in Chinese)

39) X. Z. Gong, B. Zhang, Z. Wang and Z. C. Guo: Metall. Mater. Trans. B, 45 (2014), 2050

40) S. P. Zhong, L. Guo, Z. Y. Ding and Z. C. Guo: Nonferr. Met. Sci. Eng., 9 (2018), 15 (in Chinese).

41) C. Wagner: J. Met., 4 (1952), 214

42) M. Schiller: Ph.D. thesis, RWTH Aachen, (1987), http://publications. rwth-aachen.de/record/71833? $1 \mathrm{n}=\mathrm{de}$, (accessed 2019-06-24).

43) Y. W. Zhong, Z. Wang, X. Z. Gong and Z. C. Guo: Ironmaking Steelmaking, 39 (2012), 38.

44) S. P. Matthew, T. R. Cho and P. C. Hayes: Metall. Trans. B, 21 (1990), 733.

45) S. P. Matthew and P. C. Hayes: Metall. Trans. B, 21 (1990), 153.

46) D. S. John, S. P. Matthew and P. C. Hayes: Metall. Trans. B, 15 (1984), 709

47) D. S. John, S. P. Matthew and P. C. Hayes: Metall. Trans. B, 15 (1984), 701

48) S. P. Matthew and P. C. Hayes: Metall. Trans. B, 21 (1990), 141

49) S. E. Moujahid and A. Rist: Metall. Trans. B, 19 (1988), 787.

50) R. Nicolle and A. Rist: Metall. Trans. B, 10 (1979), 429.

51) M. Rau, D. Rieck and J. W. Evans: Metall. Trans. B, 18 (1987), 257.

52) T. Yamashita, T. Nakada and K. Nagata: Metall. Mater. Trans. B, 38 (2007), 185.

53) Z. Du, Q. S. Zhu, C. L. Fan, F. Pan, H. Z. Li and Z. H. Xie: Steel Res. Int., 87 (2016), 789.

54) D. Neuschütz: Steel Res., 62 (1991), 333.

55) S. Hayashi, S. Sawai and Y. Iguchi: ISIJ Int., 33 (1993), 1078.

56) S. Hayashi and Y. Iguchi: ISIJ Int., 32 (1992), 1066.

57) F. Lu, L. Y. Wen, J. L. Li, J. Wei, J. Xu and S. F. Zhang: Comput. Mater. Sci., 125 (2016), 263.

58) F. Lu, L. Y. Wen, H. Zhong, J. Xu, S. F. Zhang, H. M. Duan and Z. Q. Yang: J. Appl. Crystallogr., 51 (2018), 1641.

59) H. Zhong, L. Y. Wen, J. L. Li, J. Xu, M. L. Hu and Z. Q. Yang: Powder Technol., 303 (2016), 100.

$60)$ L. Guo, J. T. Gao, S. P. Zhong, Q. P. Bao and Z. C. Guo: J. Iron Steel Res. Int., 26 (2019), 32.

61) L. Guo, S. P. Zhong, Q. P. Bao, J. T. Gao and Z. C. Guo: Metals, 9 (2019), 750

62) J. H. Shao: Ph.D. thesis, University of Science and Technology Beijing, (2012) (in Chinese), http://gb.oversea cnki.net/KCMS/detail/detail aspx ? filename $=1016044673$. nh $\&$ dbcode $=$ CDFD $\&$ dbname $=$ CDFD2016,$($ accessed 2019-09-12 $)$

63) T. Mikami, H. Kamiya and M. Horio: Powder Technol., 89 (1996), 231.

64) K. S. Zhu, J. J. Wang and W. G. Li: J. East China Inst. Metall., 6 (1989), 47 (in Chinese)

65) C. F. You, C. Luan and X. Wang: Powder Technol., 239 (2013), 175

66) B. Zhang and X. Z. Gong: ISIJ Int., 51 (2011), 1403.

67) J. H. Shao, Z. C. Guo and H. Q. Tang: Steel Res. Int., 84 (2012), 111

68) Y. W. Zhong, Z. Wang, Z. C. Guo and H. Q. Tang: Powder Technol., 256 (2014), 13

69) L. Guo, Z. Wang, S. P. Zhong, Q. P. Bao and Z. C. Guo: Powder Technol., 343 (2019), 683

70) H. Ono-Nakazato, T. Usui, N. Kitamura and Y. Tsubone: Miner. Process. Extr. Metall. Rev., 24 (2003), 269.

71) D. L. Blundell: Ph.D. thesis, University of Wollongong, (2005), https://ro.uow.edu.au/theses/469/, (accessed 2019-06-24).

72) W. D. Collinson: Rev. Geophys., 13 (1975), 659

$73)$ D. Hays: Fundamentals of Adhension, ed. by L. H. Lee, Plenum Press, New York, (1991), 137.

74) Y. X. Liu: J. Changchun Univ. Earth Sci., 20 (1990), 69 (in Chinese).

75) B. G. Langston and F. M. Stephens: J. Met., 12 (1960), 312

76) A. Afra: Ph.D. thesis, Royal Institute of Technology, (1967)

77) S. Hayashi, S. Sayama and Y. Iguchi: ISIJ Int., 30 (1990), 722.

78) T. Jiang and M. S. Chu: J. Benxi Coll. Metall., 1 (1999), 14 (in Chinese).

79) K. S. Zhu, J. H. Huang and W. G. Li: J. East China Inst. Metall., 6 (1989), 74 (in Chinese)

80) Y. W. Zhong, Z. Wang, Z. C. Guo and H. Q. Tang: Powder Technol., 249 (2013), 175

81) Y. L. Zhang, Z. Q. An, H. Bai, Q. Li and Z. C. Guo: Powder Technol., 284 (2015), 279

82) Z. Q. An: Ph.D. thesis, University of Science and Technology Beijing, (2018) (in Chinese), http://cdmd.cnki.com.cn/Article/ CDMD-10008-1018211510.htm, (accessed 2019-09-12).

$83)$ Z. Q. An, Y. L. Zhang, Q. Li, H. R. Wang, Z. C. Guo and J. Zhu:
Powder Technol., 328 (2018), 199.

84) J. H. Shao, Z. C. Guo and H. Q. Tang: ISIJ Int., 51 (2011), 1290.

85) B. Zhang, W. Zhi and X. Z. Gong: Powder Technol., 225 (2012), 1.

86) Y. H. Lin, Z. C. Guo and H. Q. Tang: J. Iron Steel Res. Int., 20 (2013), 8.

87) J. H. Shao, Z. C. Guo and H. Q. Tang: J. Univ. Sci. Technol. Beijing, 35 (2013), 273 (in Chinese).

88) J. F. Gransden, J. S. Sheasby and A. M. Bergougnou: Chem. Eng. Prog., 66 (1970), 208.

89) C. Pawlik, S. Schuster and N. Eder: ISIJ Int., 47 (2007), 217.

90) S. Hayashi and Y. Iguchi: ISIJ Int., 36 (1996), 1000.

91) B. Zhang, Z. Wang, X. Z. Gong and Z. C. Guo: ISIJ Int., 53 (2013), 411.

92) K. S. Zhu, W. G. Li, Y. Wang, R. H. Gan and Z. Y. Xia: J. East China Inst. Metall., 13 (1996), 42 (in Chinese).

93) J. H. Shao: Chin. J. Eng., 37 (2015), 1276.

94) S. Hayashi and Y. Iguchi: ISIJ Int., 35 (1995), 242

95) G. L. Yin: Ph.D. thesis, Chongqing University, (2014), http://cdmd. cnki.com.cn/Article/CDMD-10611-1014042821.htm, (accessed 2019-09-12).

96) G. L. Yin, L. Y. Wen and H. L. Liang: Metall. Int., 18 (2013), 35.

97) H. H. Hausner: Int. J. Powder Metall., 3 (1967), 7.

98) Y. W. Zhong, J. T. Gao, Z. Wang and Z. C. Guo: ISIJ Int., 57 (2017), 649.

99) Y. W. Zhong, Z. Wang, J. T. Gao and Z. C. Guo: Powder Technol., 301 (2016), 1144

100) Z. L. Zhao, H. Q. Tang and Z. C. Guo: J. Univ. Sci. Technol. Beijing, 33 (2011), 817 (in Chinese).

101) Z. L. Zhao, H. Q. Tang and Z. C. Guo: Non-Ferr. Met., (2012), No. 5, 43 (in Chinese).

102) Z. L. Zhao, H. Q. Tang, B. Zhang and Z. C. Guo: Sci. China Technol. Sci., 55 (2012), 3029.

103) Z. L. Zhao, H. Q. Tang, Z. C. Guo, J. H. Shao and Z. L. Wang: J. Chin. Rare Earth Soc, 28 (2010), 334.

104) X. Z. Gong, Z. L. Zhao, Z. Wang, B. Zhang, L. Guo and Z. C. Guo: Metall. Mater. Trans. B, 47 (2016), 1137

105) L. Guo, H. Gao, Z. L. Zhang and Z. C. Guo: Iron Steel, (2015), No. 6, 15 (in Chinese)

106) M. H. Khedr: ISIJ Int., 40 (2000), 309

107) U. F. Chinje and J. H. E. Jeffes: Ironmaking Steelmaking, 13 (1986), 3.

108) S. Hayashi and Y. Iguchi: ISIJ Int., 38 (1998), 1053.

109) K. S. Zhu and W. G. Li: J. East China Inst. Metall., 13 (1996), 13 (in Chinese).

110) K. S. Zhu, K. C. Lu and W. G. Li: J. East China Inst. Metall., 9 (1992), 17 (in Chinese).

111) K. S. Zhu, J. H. Huang and W. G. Li: J. East China Inst. Metall., 6 (1989), 97 (in Chinese).

112) A. A. EL-Geassy: ISIJ Int., 36 (1996), 1328.

$113)$ Z. Du, Q. S. Zhu, Y. F. Yang, C. L. Fan, F. Pan, H. Y. Sun and Z. H. Xie: Steel Res. Int., 87 (2016), 1742.

114) L. Guo, J. K. Tang, H. Q. Tang and Z. C. Guo: Mater. Today: Proc., 2S (2015), S332.

115) L. Guo, J. T. Yu, J. K. Tang, Y. H. Lin, Z. C. Guo and H. Q. Tang: J. Iron Steel Res. Int., 22 (2015), 464.

116) Y. W. Zhong, Z. Wang, Z. C. Guo and H. Q. Tang: Powder Technol., 241 (2013), 142

117) L. Guo, Z. R. Yang, J. T. Gao, Y. W. Zhong and Z. C. Guo: ISIJ Int., 56 (2016), 736.

118) L. Guo, Y. W. Zhong, J. T. Gao, Z. R. Yang and Z. C. Guo: Powder Technol., 284 (2015), 210.

119) Q. Li, V. Rudolph and W. Peukert: Powder Technol., 161 (2006), 248.

120) M. B. Ranade: Aerosol Sci. Technol., 7 (1987), 161.

121) A. N. Davis, S. A. Morton, R. M. Counce, D. W. DePaoli and M. Z. C. Hu: Colloids Surf. A, 221 (2003), 69.

122) Z. C. Xu and Z. M. Wu: Infrared Technol., 19 (1996), 25 (in Chinese).

$123)$ L. Guo, J. T. Gao, Y. W. Zhong, H. Gao and Z. C. Guo: Int. J. Miner. Metall. Mater., 23 (2016), 1019.

124) H. Fukuyama, M. K. Hossain and K. Nagata: Metall. Mater. Trans. $B, 33$ (2002), 257.

125) J. L. Li: Ph.D. thesis, Chongqing University, (2017) (in Chinese), http://cdmd.cnki.com.cn/Article/CDMD-10611-1017722429.htm, (accessed 2019-09-12).

126) M. K. Şeşen: Scand. J. Metall., 30 (2001), 1

127) T. E. Kasabgy and W. K. Lu: Metall. Trans. B, 11 (1980), 409.

128) Z. Du, Q. S. Zhu, C. L. Fan, F. Pan and Z. H. Xie: Powder Technol., 313 (2017), 82.

129) M. Chang and L. C. De Jonghe: Metall. Trans. B., 15 (1984), 685.

130) N. Shigematsu and H. Iwai: ISIJ Int., 29 (1989), 486.

131) Y. W. Zhong, Z. Wang, Z. C. Guo and H. Q. Tang: Powder Technol., 230 (2012), 225.

132) K. S. Zhu, W. J. An, Y. K. Fu, C. Z. Xia and W. G. Li: Res. Iron Steel, (2000), No. 5, 4 (in Chinese). 
133) C. Lei, S. Y. He, Z. Du, F. Pan, Q. S. Zhu and H. Z. Li: Powder Technol., 301 (2016), 608

134) C. Lei, G. Y. Zhang, Q. S. Zhu and Z. H. Xie: Powder Technol., 296 (2016), 79.

135) C. Lei, T. Zhang, J. B. Zhang, C. L. Fan, Q. S. Zhu and H. Z. Li: ISIJ Int., 54 (2014), 589.

136) C. Lei: Ph.D. thesis, Graduate University of the Chinese Academy of Sciences, (2015) (in Chinese), http://ir.ipe.ac.cn/ handle/122111/20343, (accessed 2019-09-12).

137) K. S. Zhu and W. G. Li: J. East China Inst. Metall., 13 (1996), 55.

$138)$ K. S. Zhu, W. G. Li, H. M. Xie, R. H. Gan and Z. Y. Xia: J. East China Inst. Metall., 13 (1996), 37 (in Chinese).

139) K. S. Zhu, W. G. Li and Y. S. Xiao: J. East China Inst. Metall., 13 (1996), 24 (in Chinese).

140) Q. Y. Xu, Z. Z. Liu, Z. P. Li, J. J. Wang and L. Zhou: Metals, 8 (2018), 523

141) Q. Y. Xu, Z. P. Li, Z. Z. Liu, J. J. Wang and H. C. Wang: Metals, 8 (2018), 525 .

142) T. Zhang, C. Lei and Q. S. Zhu: Powder Technol., 254 (2014), 1.

143) J. Fang and M. S. Chu: J. Northeast. Univ. Nat. Sci., 21 (2000), 80

144) Z. W. An: Master thesis, Hebei Polytechnic University, (2008) (in Chinese), http://cdmd.cnki.com.cn/Article/CDMD-10081-2009016035. $\mathrm{htm}$, (accessed 2019-09-12).

$145)$ Z. M. Zeng: J. East China Inst. Metall., 6 (1989), 11 (in Chinese).

146) L. J. Fan, Q. G. Lv and Y. J. Na: CIESC J., 61 (2010), 3228 (in Chinese).

147) L. J. Fan, Q. G. Lv, Y. J. Na and K. S. Yu: Chin. J. Process Eng., 11 (2011), 91 (in Chinese).

148) L. J. Fan: Ph.D. thesis, Graduate University of the Chinese Academy of Sciences, (2011) (in Chinese), http://cdmd.cnki.com.cn/Article/ CDMD-80135-1011153966.htm, (accessed 2019-09-12).

149) R. Haque, H. S. Ray and A. Mukherjee: ISIJ Int., 31 (1991), 1279.

150) S. W. Prabowo, R. J. Longbottom, B. J. Monaghan, D. del Puerto, M. J. Ryan and C. W. Bumby: Metall. Mater. Trans. B, 50 (2019), 1729 .

151) J. Li, J. Kong, Q. S. Zhu and H. Z. Li: AIChE J., 63 (2017), 459.

152) Q. S. Zhu, R. F. Wu and H. Z. Li: Particuology, 11 (2012), 294.

$153)$ N. S. Srinivasan: Powder Technol., 124 (2002), 28.

154) T. M. Reed and M. R. Fenske: Ind. Eng. Chem. Fundam., 47 (1955), 275.

155) Y. F. Song and Q. S. Zhu: Chin. J. Process Eng., 11 (2011), 361 (in Chinese).

156) X. P. Gu, Y. Han, J. J. Wang and L. F. Feng: J. Chem. Ind. Eng. China, (2013), No. 2, 498 (in Chinese).

157) E. K. Levy and B. Celeste: Powder Technol., 163 (2006), 41.

$158)$ Q. J. Guo, M. H. Wang, Y. Li and C. H. Yang: Chem. Eng. Technol., 28 (2005), 1117

159) C. B. Xu, Y. Cheng and J. Zhu: Powder Technol., 163 (2006), 227.

$160)$ R. D. Morse: Ind. Eng. Chem., 47 (1955), 1170.

161) Y. H. Qi and H. C. Xu: J. Iron Steel Res., 8 (1996), 7 (in Chinese).

162 B. Weiss, J. Sturn, S. Voglsam, S. Strobl, H. Mali, F. Winter and J. L. Schenk: Ironmaking Steelmaking, 38 (2011), 65.

$163)$ L. Guo, H. Gao, J. Yu, Z. L. Zhang and Z. C. Guo: Int. J. Miner Metall. Mater., 22 (2015), 12

164) H. S. Chen, Z. Zheng, Y. T. Zhang and S. W. Zou: Chin. J. Process
Eng., 13 (2013), 980 (in Chinese).

$165)$ B. Weiss, J. Sturn, S. Voglsam, S. Strobl, H. Mali, F. Winter and J. L. Schenk: Steel Res. Int., 81 (2010), 93.

166) B. Weiss, J. Sturn, F. Winter and J. L. Schenk: Ironmaking Steelmaking, 36 (2009), 212.

167) M. S. Chu and J. Fang: J. Northeast. Univ. Nat. Sci., 22 (2001), 140 (in Chinese).

168) M. S. Chu and J. Fang: J. Northeast. Univ. Nat. Sci., 23 (2002), 32 (in Chinese).

169) Y. F. Liu: Ph.D. thesis, Zhejiang University, (2007) (in Chinese).

170) W. G. Su: Master thesis, Tianjin University of Science\&Technology, (2009) (in Chinese), http://cdmd.cnki.com.cn/Article/CDMD10057-2009256239.htm, (accessed 2019-09-12).

171) S. Y. He, H. Y. Sun, C. Q. Hu, J. Li, Q. S. Zhu and H. Z. Li: Powder Technol., 313 (2017), 161.

172) M. Ozawa: Tetsu-to-Hagané, 59 (1973), 361 (in Japanese).

173) M. Ozawa and M. Tanaka: Tetsu-to-Hagané, 58 (1972), 821 (in Japanese).

174) F. Tsukihashi, K. Kato, K. Ostuka and T. Sōma: Tetsu-to-Hagané, 68 (1982), 750 (in Japanese)

175) S. Hayashi and Y. Iguchi: ISIJ Int., 34 (1994), 555.

$176)$ N. J. Themelis and W. H. Gauvin: AIChE J., 8 (1962), 437

177) Y. K. Rao: Metall. Trans. B, 10 (1979), 243.

178) N. Takeuchi, Y. Nomura, K. Ohno, T. Maeda, K. Nishioka and M. Shimizu: ISIJ Int., 47 (2007), 386.

179) H. T. Wang and H. Y. Sohn: Metall. Mater. Trans. B, 44 (2013), 133.

180) H. Y. Sohn and Y. Mohassab: J. Sustain. Metall., 2 (2016), 216.

181) M. E. Choi and H. Y. Sohn: Ironmaking Steelmaking, 37 (2010), 81.

$182)$ J. H. Shao, Z. C. Guo and H. Q. Tang: ISIJ Int., 51 (2011), 1290.

183) Editorial office: China Steel Focus, (2012), No. 3, 4 (in Chinese).

184) L. Guo: Ph.D. thesis, University of Science and Technology Beijing, (2016) (in Chinese), http://cdmd.cnki.com.cn/Article/ CDMD-10008-1016044673.htm, (accessed 2019-09-12).

185) L. Guo, J. T. Gao, Y. W. Zhong and Z. C. Guo: ISIJ Int., 55 (2015), 1797.

186) B. Abolpour, M. M. Afsahi, A. S. Goharrizi and M. Azizkarimi: Ironmaking Steelmaking, 44 (2016), 750

187) B. Abolpour, M. M. Afsahi and A. S. Goharrizi: Chem. Prod. Process Model., 14 (2018), 1.

188) B. Abolpour, M. M. Afsahi, A. S. Goharrizi and M. Azizkarimi: Chem. Prod. Process Model., 12 (2016), 1.

189) B. Abolpour, M. M. Afsahi, A. S. Goharrizi and M. Azizkarimi: Ironmaking Steelmaking, 46 (2019), 1.

190) B. Abolpour, M. M. Afsahi, A. S. Goharrizi and M. Azizkarimi: Heat Mass Transf., 53 (2017), 3517.

191) B. Abolpour, M. M. Afsahi, A. S. Goharrizi and M. Azizkarimi: Heat Mass Transf., 53 (2017), 2409.

192) Z. Zhong, H. S. Chen, K. Wu, J. Y. Long and W. Z. Hu: China Metall. News, (2014), No. 6, 1 (in Chinese).

193) J. L. Schenk: Particuology, 9 (2011), 14.

194) P. Weber, M. Hirsch, W. Bresser and R. Husain: Ironmaking Proc., Vol. 53, Iron and Steel Society, London, (1994), 491.

195) S. Qiu: Sinter. Pelletizing, 20 (1995), 38 (in Chinese) 